\title{
Cryo-sensitive aggregation triggers NLRP3 inflammasome assembly in cryopyrin-associated periodic syndrome
}

\author{
Tadayoshi Karasawa ${ }^{1 *}$, Takanori Komada ${ }^{1}$, Naoya Yamada $^{1}$, Emi Aizawa ${ }^{1}$, \\ Yoshiko Mizushina $^{1}$, Sachiko Watanabe ${ }^{1}$, Chintogtokh Baatarjav ${ }^{1}$, \\ Takayoshi Matsumura ${ }^{1}$, Masafumi Takahashi ${ }^{1 *}$ \\ ${ }^{1}$ Division of Inflammation Research, Center for Molecular Medicine, \\ Jichi Medical University, Tochigi, Japan
}

Running title: Cryo-sensitive assembly of NLRP3 inflammasome

*Correspondence:

Tadayoshi Karasawa, $\mathrm{PhD}$ or Masafumi Takahashi, MD, PhD

Division of Inflammation Research

Center for Molecular Medicine

Jichi Medical University

3311-1 Yakushiji, Shimotsuke, Tochigi 329-0498, Japan

Tel/ Fax: +81-285-58-7446/+81-285-44-5365

E-mail: tdys.karasawa@jichi.ac.jp or masafumi2@jichi.ac.jp

Keywords: cytokines; inflammation; interleukin

Total word count: 5,870 words, 7 figures, 10 supplemental figures, and 2 videos 


\begin{abstract}
Cryopyrin-associated periodic syndrome (CAPS) is an autoinflammatory syndrome caused by mutations of NLRP3, which was originally identified as cryopyrin. Familial cold autoinflammatory syndrome (FCAS), the mildest form of CAPS, is characterized by coldinduced inflammation induced by the overproduction of IL-1 $\beta$. However, the molecular mechanism of how mutated NLRP3 causes inflammasome activation in CAPS remains unclear. Here, we found that CAPS-associated NLRP3 mutants form cryo-sensitive aggregates that function as a scaffold for inflammasome activation. Cold exposure promoted inflammasome assembly and subsequent IL-1 $\beta$ release triggered by mutated NLRP3. While $\mathrm{K}^{+}$efflux was dispensable, $\mathrm{Ca}^{2+}$ was indispensable for mutated NLRP3-mediated inflammasome assembly. Notably, $\mathrm{Ca}^{2+}$ influx was induced during mutated NLRP3-mediated inflammasome assembly. Furthermore, caspase-1 inhibition prevented $\mathrm{Ca}^{2+}$ influx and inflammasome assembly induced by the mutated NLRP3, suggesting a feed-forward $\mathrm{Ca}^{2+}$ influx loop triggered by mutated NLRP3. Thus, the mutated NLRP3 forms cryo-sensitive aggregates to promote inflammasome assembly distinct from canonical NLRP3 inflammasome activation.
\end{abstract}

\title{
Abbreviations
}

ASC, apoptosis-associated speck-like protein containing a caspase recruitment domain; CAPS, cryopyrin-associated periodic syndromes; CINCA, chronic infantile neurological, cutaneous and articular syndrome; DAMP, damage/danger-associated molecular pattern; DOX, doxycycline; FCAS, familial cold autoinflammatory syndrome; FRAP, fluorescence recovery after photobleaching; GSDMD, gasdermin D; IL, interleukin; LLPS, liquid-liquidphase separation; MWS, Muckle-Wells syndrome; NLRP3, nucleotide-binding oligomerization domain, leucine-rich repeat and pyrin domain containing 3; PRR, pattern recognition receptor; $\mathrm{RCD}$, regulated cell death 


\section{Introduction}

The cryopyrin-associated periodic syndromes (CAPS) are a spectrum of rare diseases consisting of three clinically defined autosomal dominant disorders: familial cold autoinflammatory syndrome (FCAS), Muckle-Wells syndrome (MWS), and chronic infantile neurological, cutaneous and articular syndrome (CINCA) (Kuemmerle-Deschner et al., 2017). These three syndromes can be classified according to severity. FCAS is the mildest form of CAPS and is characterized by cold-induced fever and inflammation. MWS is accompanied by systemic amyloidosis and hearing loss. CINCA is the most severe phenotype and is characterized by central nervous system inflammation and bone deformities. Genetic causes of these disorders are gain-of-function mutations in the Nucleotide-binding oligomerization domain, leucine-rich repeat and pyrin domain containing 3 (NLRP3) gene, also known as cryopyrin (Brydges et al., 2009; Kuemmerle-Deschner, 2015). The mutated NLRP3 protein causes overproduction of interleukin(IL)-1 $\beta$, resulting in systemic inflammatory characteristics, such as recurrent fever, rash, conjunctivitis, and arthralgia.

NLRP3 forms a multi-protein molecular complex called "NLRP3 inflammasome" (Schroder and Tschopp, 2010). NLRP3 inflammasome is composed of NLRP3, apoptosisassociated speck-like protein containing a caspase recruitment domain (ASC) which acts as an adaptor protein, and the cysteine proteinase caspase-1, and functions as a scaffold for caspase1 activation (Schroder and Tschopp, 2010; Karasawa and Takahashi, 2017). The assembly of inflammasome complex promotes oligomerization and auto-processing of caspase-1. The active caspase-1 processes precursors of inflammatory cytokines IL-1 $\beta$ and IL-18 and converts them to their mature forms. Another critical role of caspase-1 is the processing of gasdermin D (GSDMD) (Liu et al., 2016; Broz et al., 2020). The processed amino-terminal domain of GSDMD binds to the plasma membrane and forms pores. Therefore, caspase-1-mediated GSDMD pore induces the release of cytosolic content and subsequent necrotic cell death called pyroptosis.

Although NLRP3 was initially identified as a causative gene of CAPS (Feldmann et al., 2002), the function of NLRP3 had been unclear because CAPS is a rare disease. In 2006, however, Tschopp and his colleagues found that monosodium urate crystals activate NLRP3 
inflammasome (Martinon et al., 2006). Since this finding, many studies have clarified the pivotal role of NLRP3 inflammasome in inflammatory responses in both host defense and sterile inflammatory diseases. Other investigators and we have demonstrated the pathophysiological role of NLRP3 inflammasome in cardiovascular and renal diseases (Duewell et al., 2010; Usui et al., 2012, 2015; Komada et al., 2014,2015).

Despite many findings regarding molecular mechanisms and the pathophysiological role of the NLRP3 inflammasome, the disease mechanisms of CAPS are not fully understood. In particular, although FCAS is characterized by cold exposure-induced recurrent fever and inflammation, the mechanisms by which exposure to cold regulates NLRP3 inflammasome in FCAS remain unclear (Rosengren et al., 2007; Brydges et al., 2013). In the present study, we have found that CAPS-associated NLRP3 mutants form cryo-sensitive aggregates, which function as scaffolds for NLRP3 inflammasome assembly. The aggregation of the mutated NLRP3 is sensitive to $\mathrm{Ca}^{2+}$. Therefore, mutated NLRP3 triggers inflammasome assembly driven by $\mathrm{Ca}^{2+}$ influx-mediated feed-forward regulation.

\section{Results}

\section{CAPS-associated NLRP3 mutants form cryo-sensitive foci}

To investigate the pathophysiological role of CAPS-associated NLRP3 mutants, we generated cell lines expressing fusion proteins of NLRP3 mutants and a green monomeric protein, mNeonGreen (Figure 1-figure supplement1A and B). We found that FCAS-associated NLRP3-L353P and CINCA-associated NLRP3-D303N formed foci without any stimulation, while wild type (WT)-NLRP3 is expressed diffusely (Figure 1A). On the other hand, ASC-GFP forms a single speck per cell. To analyze the localization of NLRP3 during NLRP3 inflammasome activation without being affected by ASC, we generated ASC KO THP-1 cells (ASC KO/EF-1-NLRP3-mNeonGreen-THP-1). NLRP3-D303N formed foci in ASC KO THP-1 cells, whereas WT-NLRP3 did not form foci upon stimulation by the NLRP3 activator nigericin, indicating that the foci are distinct from canonical inflammasome assembly (Figure 1B and C). To assess whether the foci formation is cryo-sensitive, the transduced cells were exposed to cold temperature $\left(32^{\circ} \mathrm{C}\right)$ for $24 \mathrm{~h}$. A considerable number of foci were detected only in D303N 
bioRxiv preprint doi: https://doi.org/10.1101/2021.10.05.463273; this version posted October 29, 2021. The copyright holder for this preprint (which was not certified by peer review) is the author/funder, who has granted bioRxiv a license to display the preprint in perpetuity. It is made available under aCC-BY-NC-ND 4.0 International license.

A

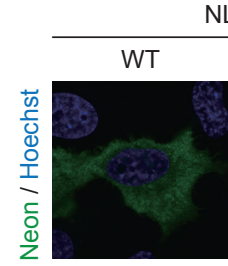

NLRP3-mNeonGreen
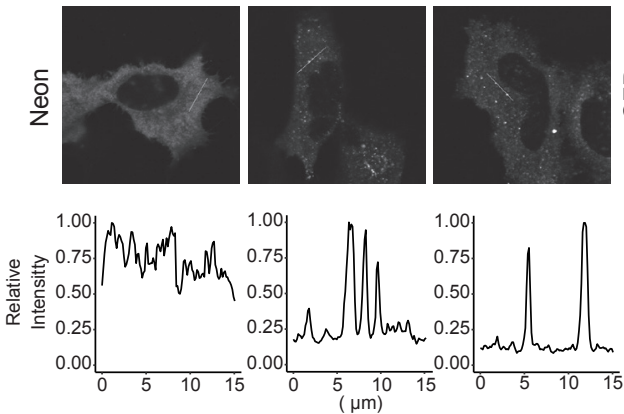

$\mathrm{D}$
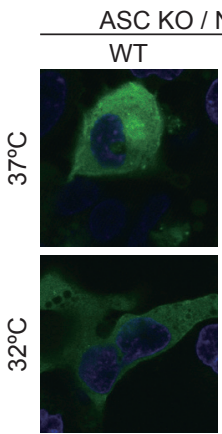

E

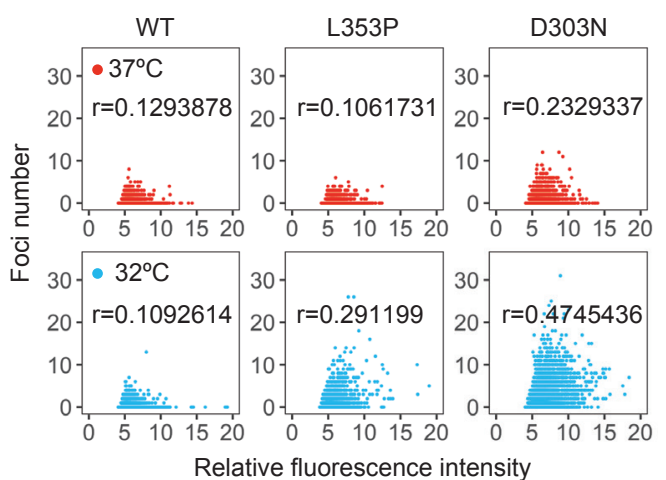

$\mathrm{F}$

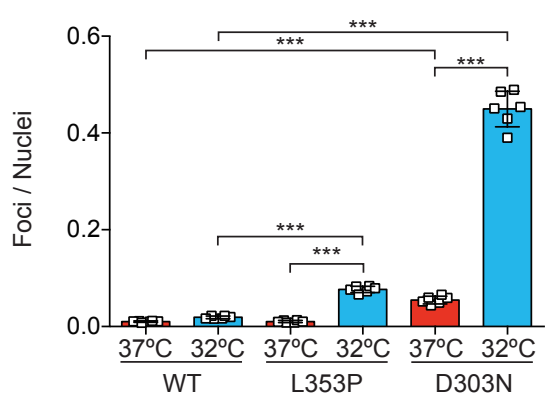

B

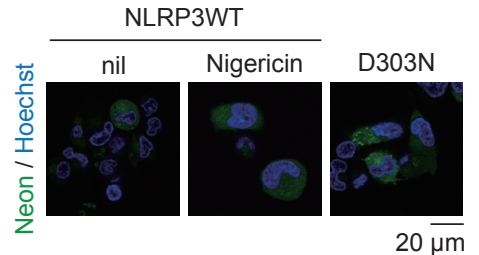

C
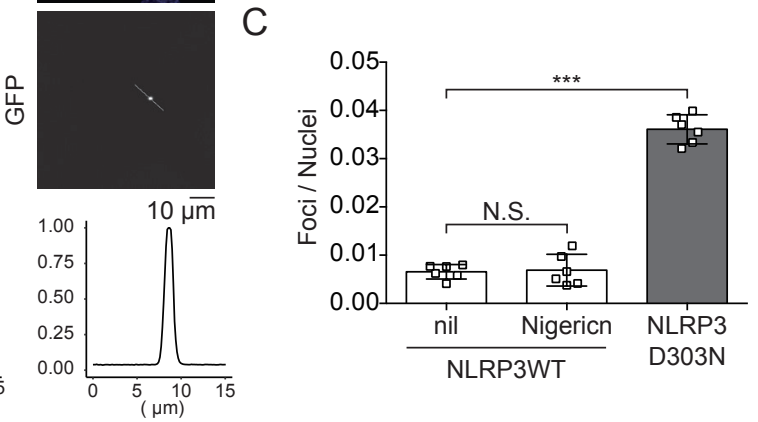

ASCGFP

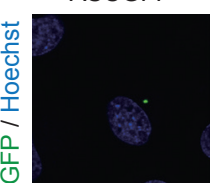

G

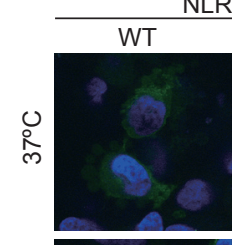

NLRP3-mNeonGreen-Hela

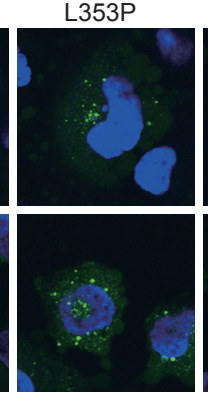

$\mathrm{H}$

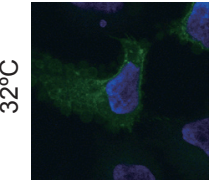

$30 \sqrt{\cdot 37^{\circ} \mathrm{C}}$

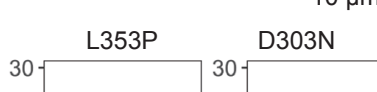

$20-r=0.1673756$

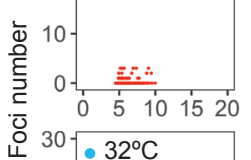

$30-32^{\circ} \mathrm{C}$
$20-r=0.1497256$

20

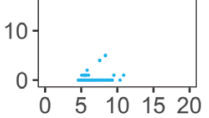

$20-r=0.321773920-r=0.3562124$

$10-$

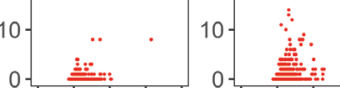

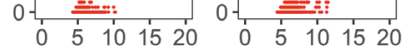

$30-30-$

$20-r=0.396933920-r=0.5245447$

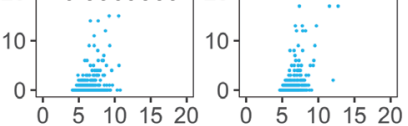

Relative fluorescence intensity

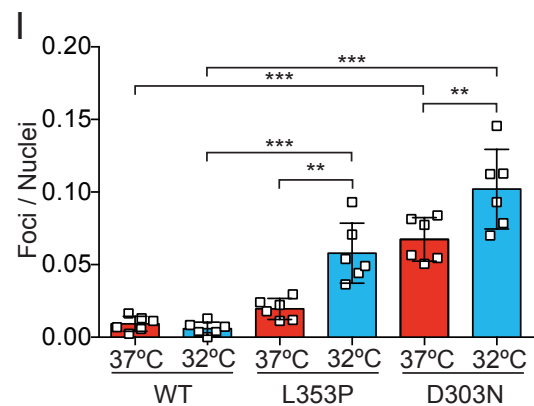

Figure 1. CAPS-associated NLRP3 mutants form cryo-sensitive foci.

(A) EF1-NLRP3-WT-, NLRP3-L353P-, or NLRP3-D303N-mNeonGreen-Hela cells or EF1-ASCGFP-Hela cells were analyzed by confocal microscopy. Line profiles of foci or specks in the images were analyzed. (B and C) ASC KO/EF1-NLRP3-WT-, or NLRP3-D303N-mNeonGreen-THP-1 cells were differentiated with $200 \mathrm{nM}$ PMA for $24 \mathrm{~h}$ and then treated with nigericin for 6 h. (B) Representative images by confocal microscopy. (C) The number of foci was counted by high content analysis. (D-F) Differentiated ASC KO/EF1-NLRP3-WT-, NLRP3-L353P-, or NLRP3-D303N-mNeonGreen-THP-1 cells were cultured at $37^{\circ} \mathrm{C}$ or $32^{\circ} \mathrm{C}$ for $24 \mathrm{~h}$. (G-I) EF1-NLRP3-WT-, NLRP3-L353P-, or NLRP3-D303N-mNeonGreen-HeLa cells were cultured at $37^{\circ} \mathrm{C}$ or $32^{\circ} \mathrm{C}$ for $24 \mathrm{~h}$. (D and G) Representative images by confocal microscopy. (E, F, H, I) The number of foci and the fluorescence intensity of the cells were analyzed by high content analysis. Pearson correlation coefficients are shown. (J) EF1-ASC-GFP- HeLa cells were cultured at $37^{\circ} \mathrm{C}$ or $32^{\circ} \mathrm{C}$ for $24 \mathrm{~h}$. The number of nuclei and speck was counted. (C, F, I, J) Data are expressed as the mean \pm SD. ${ }^{*} P<0.05,{ }^{* *} P<0.01,{ }^{* *} P<0.005$ as determined by two-way ANOVA with a post hoc test. Data are representative of three independent experiments. 
bioRxiv preprint doi: https://doi.org/10.1101/2021.10.05.463273; this version posted October 29, 2021. The copyright holder for this preprint (which was not certified by peer review) is the author/funder, who has granted bioRxiv a license to display the preprint in perpetuity. It is made available under aCC-BY-NC-ND 4.0 International license.

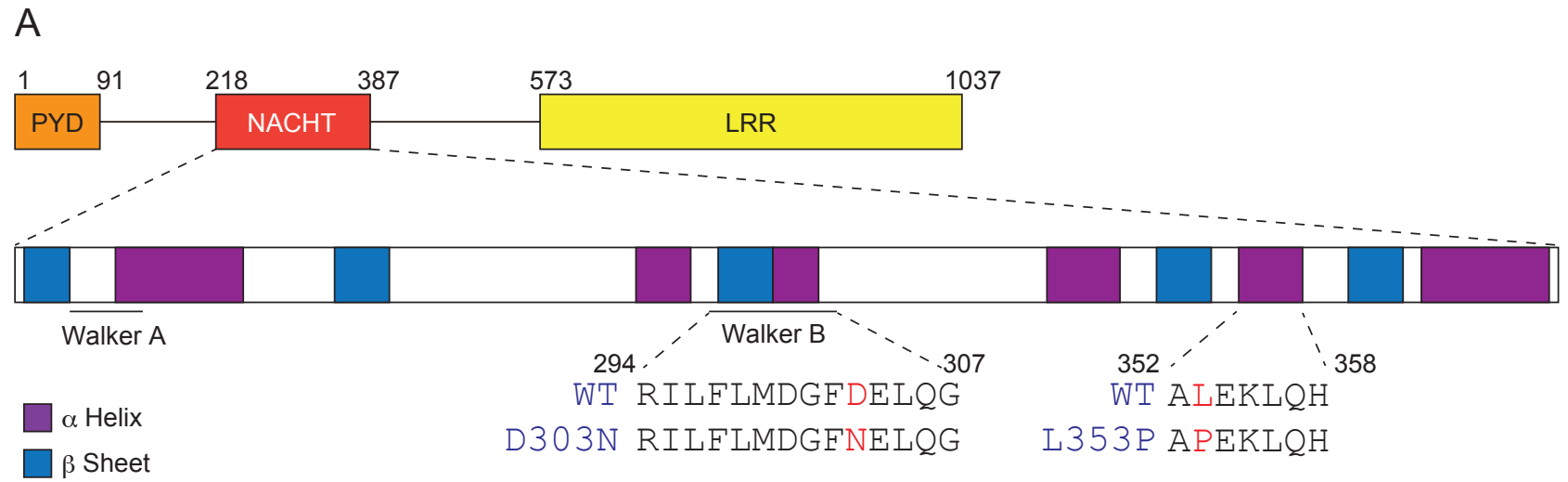

B

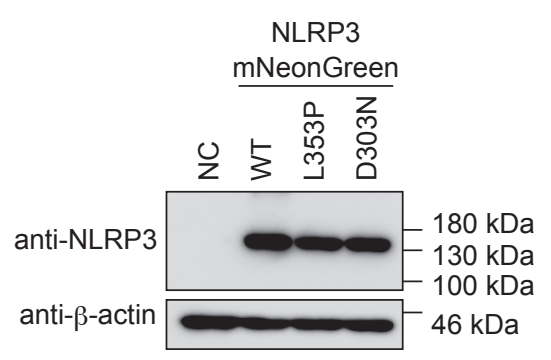

C

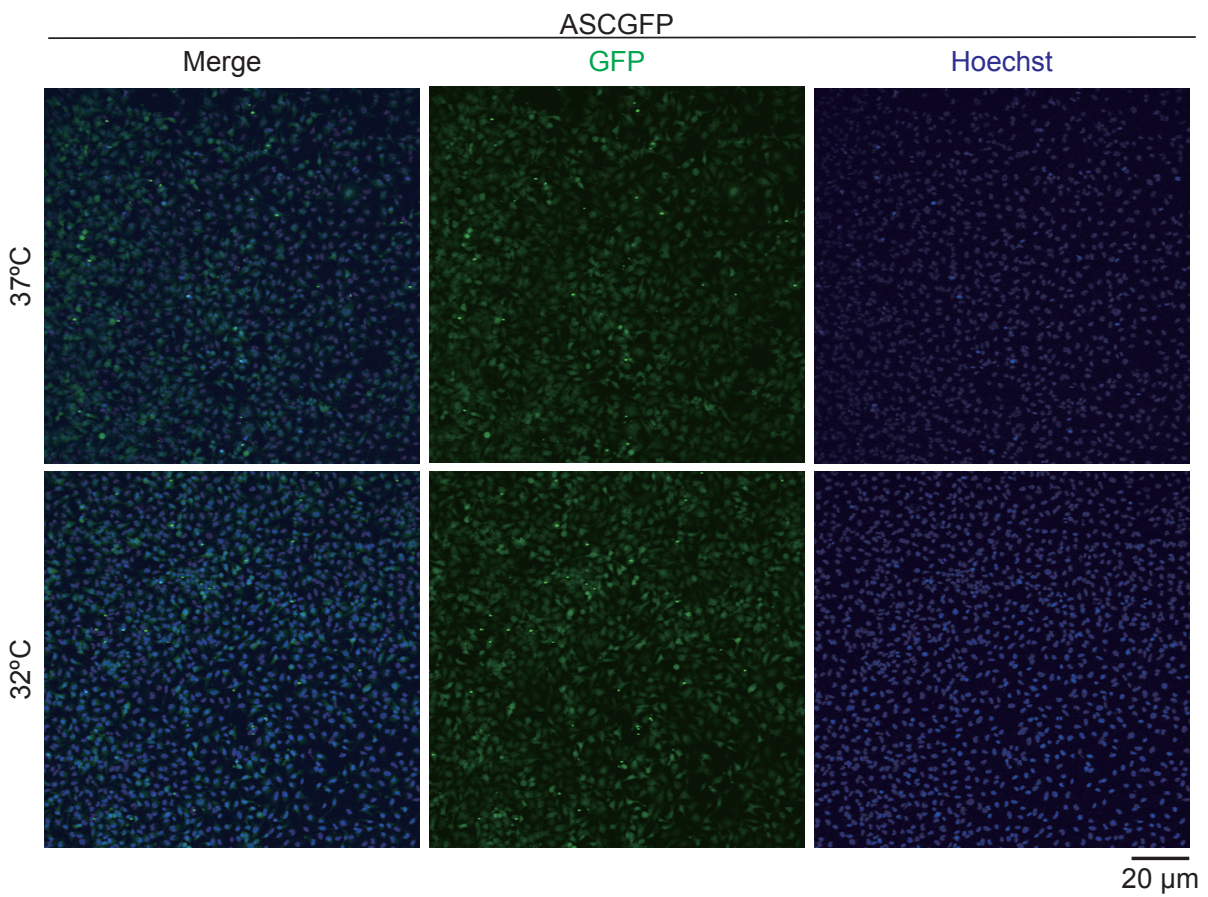

Figure 1 - figure supplement 1. Expression of NLRP3-mNeonGreen and ASC-GFP

(A) Amino acid sequence of CINCA-associated D303N mutant and FCAS-associated L353P mutant. (B)Lysates of EF1-NLRP3-WT-, NLRP3-L353P-, or NLRP3-D303N-mNeonGreen HeLa cells were analyzed by western blot. (C) EF1-ASC-GFP- HeLa cells were cultured at $37^{\circ} \mathrm{C}$ or $32^{\circ} \mathrm{C}$ for $24 \mathrm{~h}$. Representative image of confocal microscopy. 
mutant-expressing cells under normal temperature $\left(37^{\circ} \mathrm{C}\right)$. However, the number of foci was increased both in FCAS-associated L353P and CINCA-associated D303N mutant-expressing cells under cold exposure (Figure 1D-I). The number of foci formed was weakly associated with expression levels of NLRP3 as indicated by fluorescence of mNeonGreen. In contrast, speck formation by ASC-GFP was not affected by cold exposure (Figure 1J and Figure 1-figure supplement1C). These results suggest that CAPS-associated NLRP3 mutants form cryosensitive foci consistent with disease severity and characteristics.

\section{CAPS-associated NLRP3 mutants form aggregates}

Since NLRP3 has a PYD scaffold domain (Figure 2-figure supplement 1A), a common feature of molecules that form aggregates or liquid-liquid-phase separation (LLPS), we hypothesized that CAPS-associated NLRP3 mutants form aggregates or LLPS (Alberti et al., 2019). To test this hypothesis, we performed fluorescence recovery after photobleaching (FRAP) analysis. After induction of foci formation by cold exposure, some of the NLRP3L353P- and D303N-mNeonGreen-foci were bleached. The fluorescence in the bleached area was not recovered, indicating that the foci are aggregates (Figure 2A and B, Figure 2-figure supplement 2A and B). The fully bleached area of NLRP3-L353P-mNeonGreen-foci was also not recovered (Figure 2-figure supplement 2C and D). Similar results are obtained from FRAP analysis of ASC speck, initially reported to be aggregates (Masumoto et al., 1999) (Figure 2C and D). In both NLRP3-L353P foci and ASC speck, the exchange of protein between bleached and unbleached area was not detected (Figure 2E and F). Furthermore, 1,6-hexanediol, an LLPS inhibitor, did not affect foci formation of NLRP3-mNeonGreen (Figure 2-figure supplement 2E). These results suggest that foci formed by CAPS-associated NLRP3 mutants are aggregates.

Aggregates formed by CAPS-associated NLRP3 mutants are the scaffold for inflammasome activation

Next, we investigated whether aggregates formed by mutated NLRP3 function as a scaffold for inflammasome assembly and trigger subsequent IL- $1 \beta$ release. In order to analyze colocalization of NLRP3 and ASC, we developed THP-1 cells harboring two reporters; TRE- 
bioRxiv preprint doi: https://doi.org/10.1101/2021.10.05.463273; this version posted October 29, 2021. The copyright holder for this preprint (which was not certified by peer review) is the author/funder, who has granted bioRxiv a license to display the preprint in perpetuity. It is made available under aCC-BY-NC-ND 4.0 International license.

A

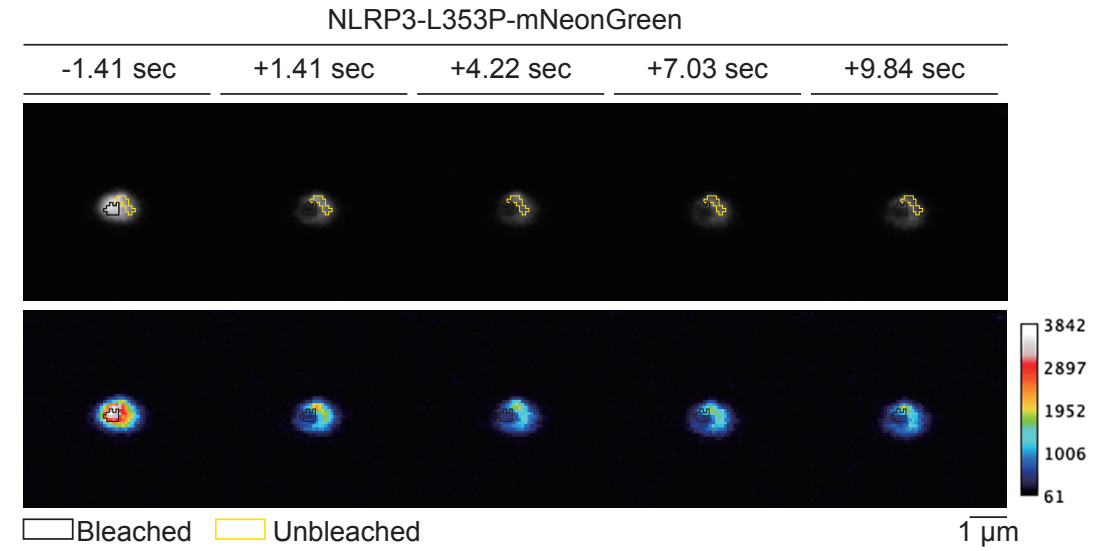

C
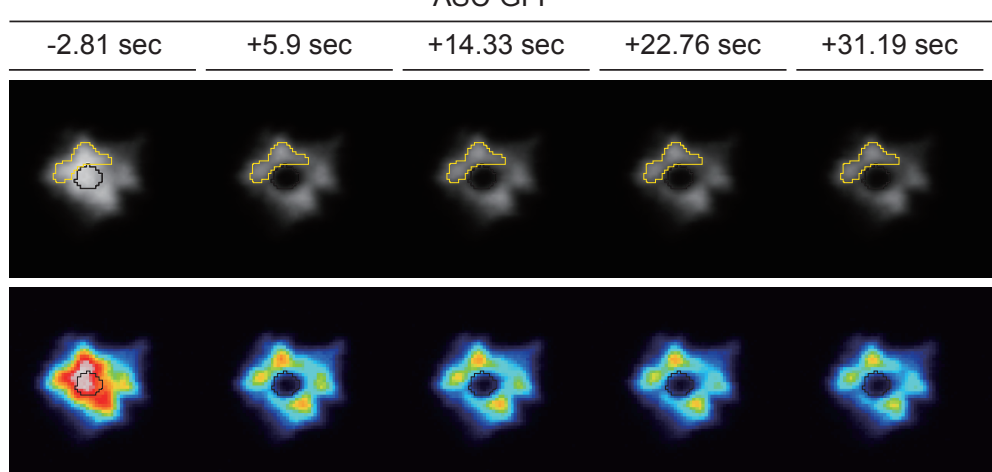

Bleached

Unbleached

E

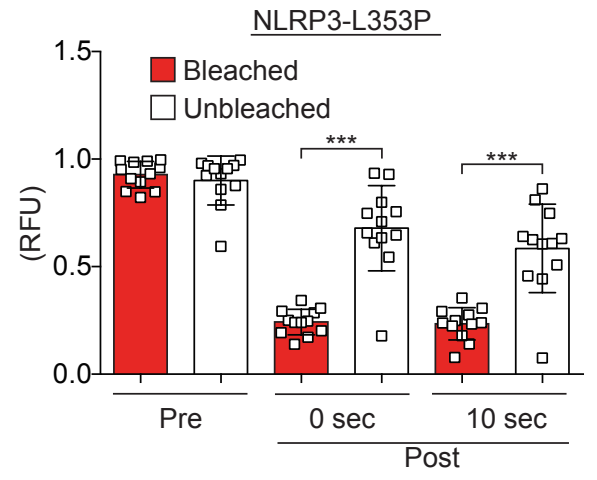

B

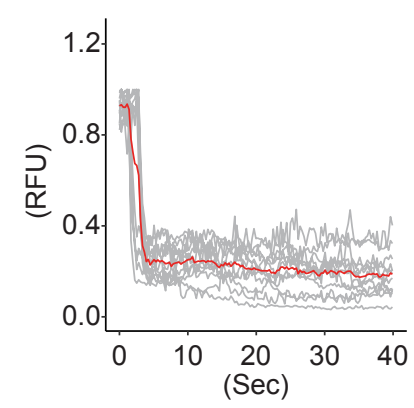

D

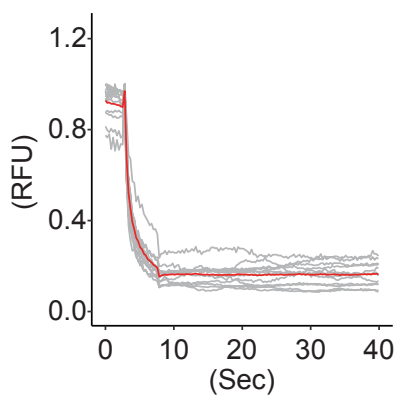

ASC

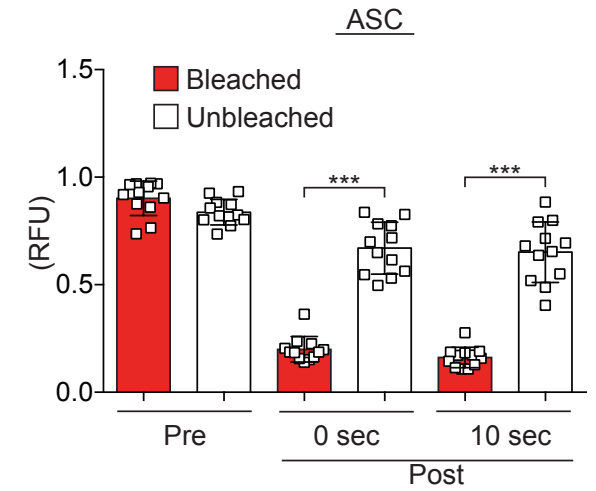

Figure 2. CAPS-associated NLRP3 mutants form aggregates

(A-F) EF1-NLRP3-L353P-mNeonGreen- or EF1-ASC-GFP-HeLa cells were cultured at $32^{\circ} \mathrm{C}$ for $24 \mathrm{~h}$. Foci or specks in the cells were analyzed by FRAP. Representative images of (A) foci formed by NLRP3-L353P-mNeonGreen or (C) specks formed by ASC-GFP before and after photobleaching. The bleached and unbleached areas are shown in black lines and yellow lines, respectively. Plots of relative fluorescence units during photobleaching of ( $\mathrm{B}$ and $\mathrm{E})$

NLRP3-L353Pm-NeonGreen $(n=12)$ and $(D$ and F) ASC specks $(n=12)$. ( $B$ and $D)$ The red line represents mean values and the gray lines represent each measurement. (E and F) Data are expressed as the mean $\pm \mathrm{SD}$. ${ }^{*} P<0.05,{ }^{* *} P<0.01$, ${ }^{* * *} P<0.005$ as determined by two-way ANOVA with a post hoc test. Data are from three independent live-cell imaging. 


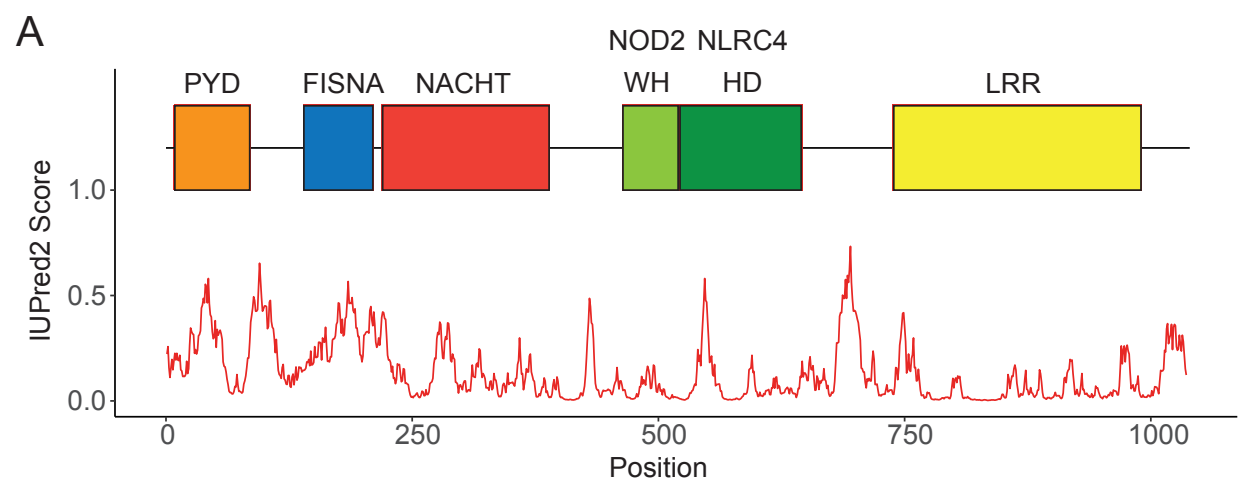

Figure 2 - figure supplement 1 . Domains composing NLRP3

(A) IUPred score of NLRP3 and domains in human NLRP3. 
bioRxiv preprint doi: https://doi.org/10.1101/2021.10.05.463273; this version posted October 29, 2021. The copyright holder for this preprint (which was not certified by peer review) is the author/funder, who has granted bioRxiv a license to display the preprint in perpetuity. It is made available under aCC-BY-NC-ND 4.0 International license.

A

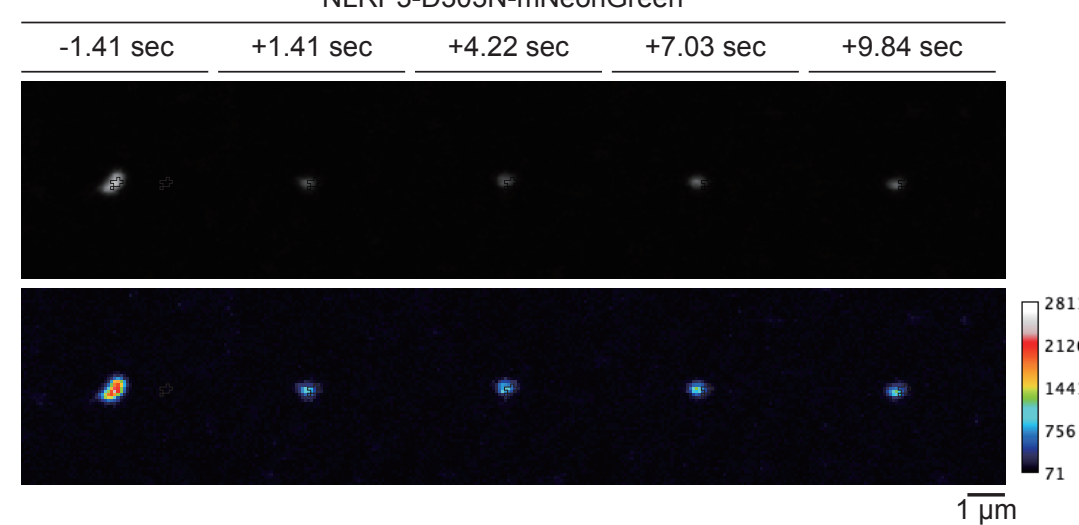

C
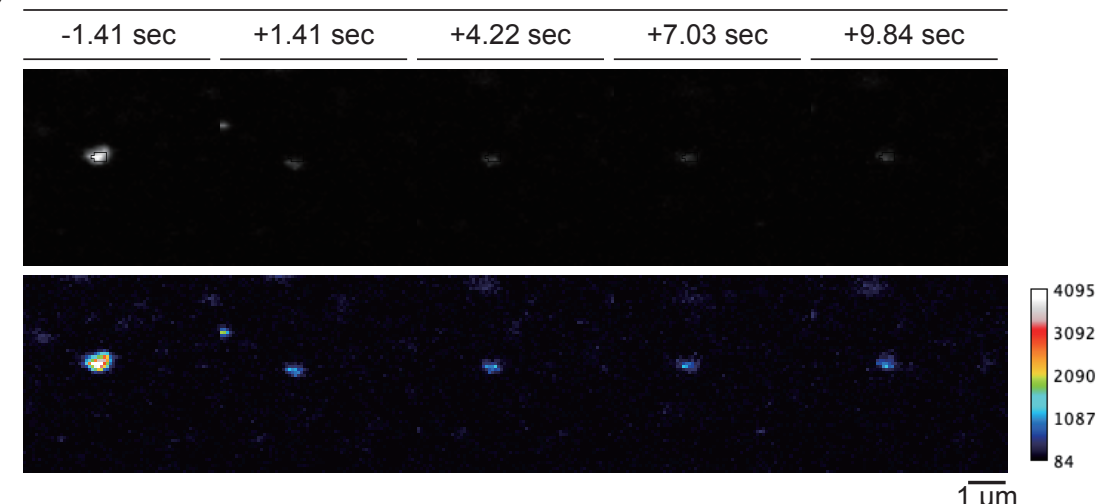

B

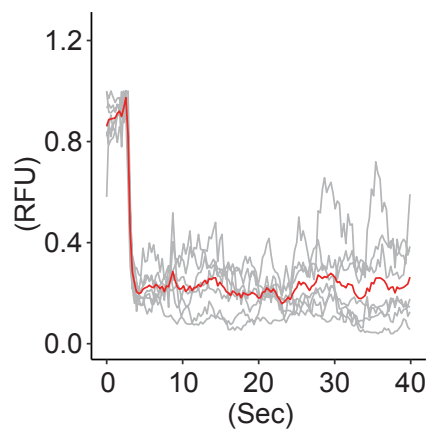

$\mathrm{D}$

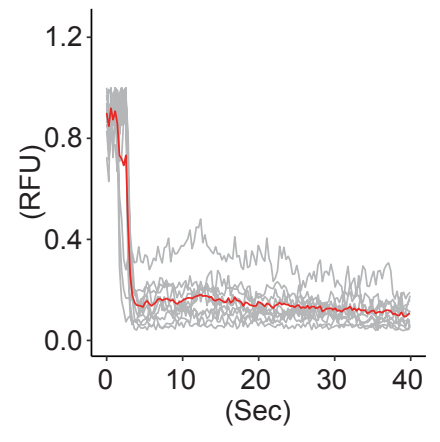

$E$ NLRP3-L353P-mNeonGreen NLRP3-D303N-mNeonGreen
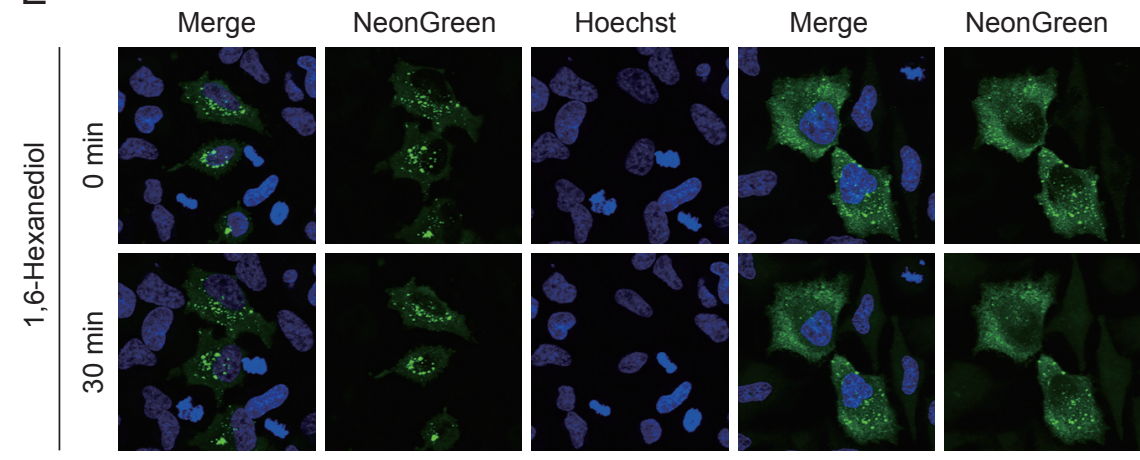

Hoechst
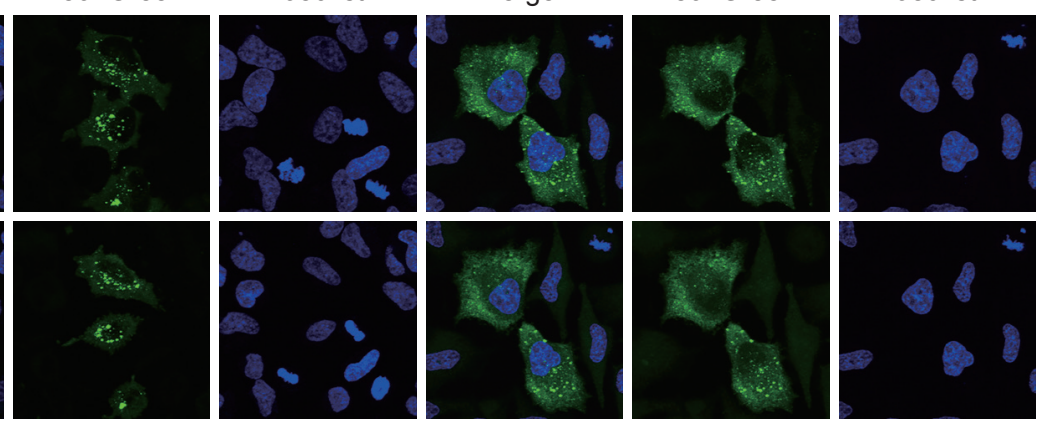

$10 \overline{\mu \mathrm{m}}$

Figure 2 - figure supplement 2. CAPS-associated NLRP3 mutants form aggregates

(A-D) EF1-NLRP3-L353P-, or NLRP3-D303N-mNeonGreen HeLa cells were cultured at $32^{\circ} \mathrm{C}$ for $24 \mathrm{~h}$. Foci in the cells were analyzed by fluorescence recovery after photobleaching. Representative images of foci formed (A) by

NLRP3-D303N-mNeonGreen or (C) by NLRP3-L353P-mNeonGreen before and after photobleaching. The bleached area and unbleached area are shown in black lines and yellow lines, respectively. Plot of relative fluorescence unit during photobleaching of (B) NLRP3-D303N-mNeonGreen $(\mathrm{n}=7)$ and $(\mathrm{D})$ NLRP3-L353P-mNeonGreen $(\mathrm{n}=10)$. The red line represents the mean value and the gray lines represent each measurement. Data are from two or three independent live-cell imaging. (E) EF1-NLRP3-L353P-, or NLRP3-D303N-mNeonGreen HeLa cells were treated with 5\% 1,6-Hexanediol for $30 \mathrm{~min}$. Representative images of live-cell imaging. 
NLRP3-mNeonGreen and EF1-ASC-BFP. After induction of NLRP3-L353P-mNeonGreen by doxycycline (DOX), ASC-speck was colocalized with the NLRP3 mutant-formed aggregate. (Figure $3 \mathrm{~A}-\mathrm{C}$ ). To exclude the possibility that NLRP3 mutant aggregation is due to its fluorescent tag, the cells expressing NLRP3 mutants under TET-ON promoter were developed (Figure 3-figure supplement 1A and B). In accordance with the cryo-sensitive formation of aggregates by NLRP3-L353P, insoluble complex formation and oligomerization of ASC induced by NLRP3-L353P were enhanced by cold exposure (Figure 3D and E). In contrast, the ASC-oligomerization induced by nigericin was attenuated under cold exposure (Figure 3F). ASC-speck formation was further assessed by fusion protein of ASC-GFP reporter. Similarly, NLRP3-L353P-induced ASC speck formation was increased under cold exposure (Figure 3G). Moreover, cold exposure enhanced IL-1 $\beta$ release induced by the NLRP3-L353P mutant, whereas nigericin- and nanosilica-induced IL-1 $\beta$ release was restrained under cold exposure (Figure 3H and Figure 3-figure supplement 1C). Cold exposure also enhanced IL-1 $\beta$ release in CINCA-associated NLRP3-D303N-expressing cells (Figure 3-figure supplement 1D). In contrast, WT-NLRP3 failed to induce IL-1 $\beta$ release (Figure 3-figure supplement 1E and F). These results demonstrate that cryo-sensitive aggregates formed by CAPS-associated NLRP3 mutants function as a scaffold for inflammasome activation and induce subsequent IL-1 $\beta$ release.

\section{$\mathrm{Ca}^{2+}$ is required for NLRP3 mutant-mediated inflammasome assembly}

To elucidate the regulatory mechanisms of NLRP3 mutant-mediated inflammasome activation under cold exposure, the upstream pathways of canonical inflammasome including $\mathrm{K}^{+}$efflux, lysosomal destabilization, mitochondrial $\mathrm{ROS}$ generation, and $\mathrm{Ca}^{2+}$ mobilization were explored. Unexpectedly, inhibition of $\mathrm{K}^{+}$efflux failed to prevent NLRP3-L353P mutantinduced IL-1 $\beta$ release, while it inhibited nigericin-induced IL-1 $\beta$ release (Figure 4-figure supplement 1A). Similarly, deficiency of NEK7, an essential component $\mathrm{K}^{+}$efflux-mediated NLRP3 inflammasome, failed to inhibit NLRP3-L353P mutant-mediated IL-1 $\beta$ release, although it inhibited nigericin-induced IL-1 $\beta$ release (Figure 4-figure supplement 1B-D). Further, inhibition of lysosomal or mitochondrial ROS pathway did not suppress NLRP3- 
A

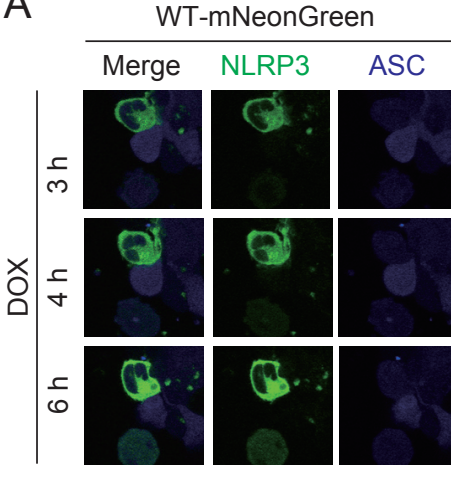

D

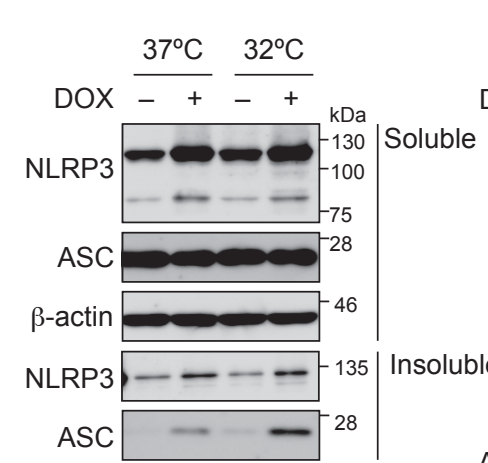

G ASC-GFP / DAPI $37^{\circ} \mathrm{C}$

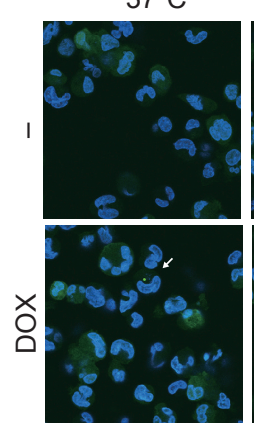

L353P-mNeonGreen

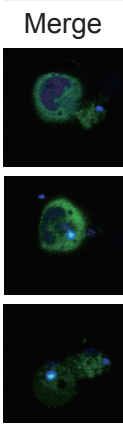

$E$

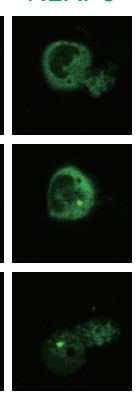

B

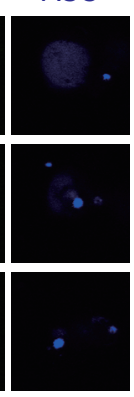

$20 \mu \mathrm{m}$

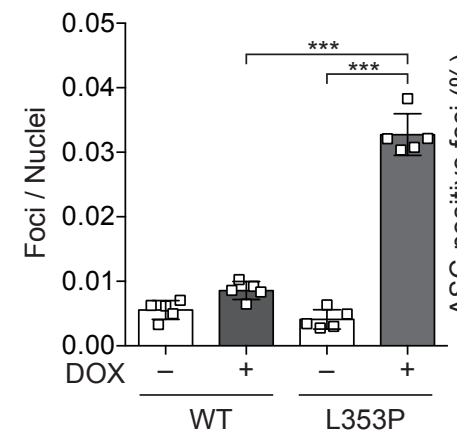

$\mathrm{F}$
C

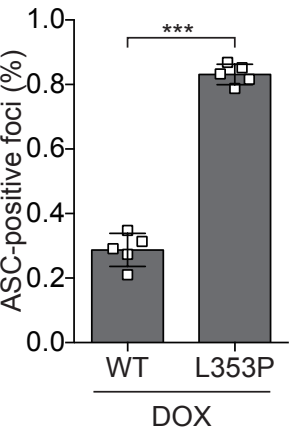

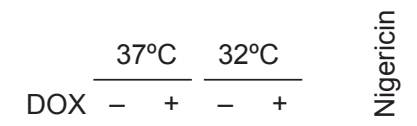
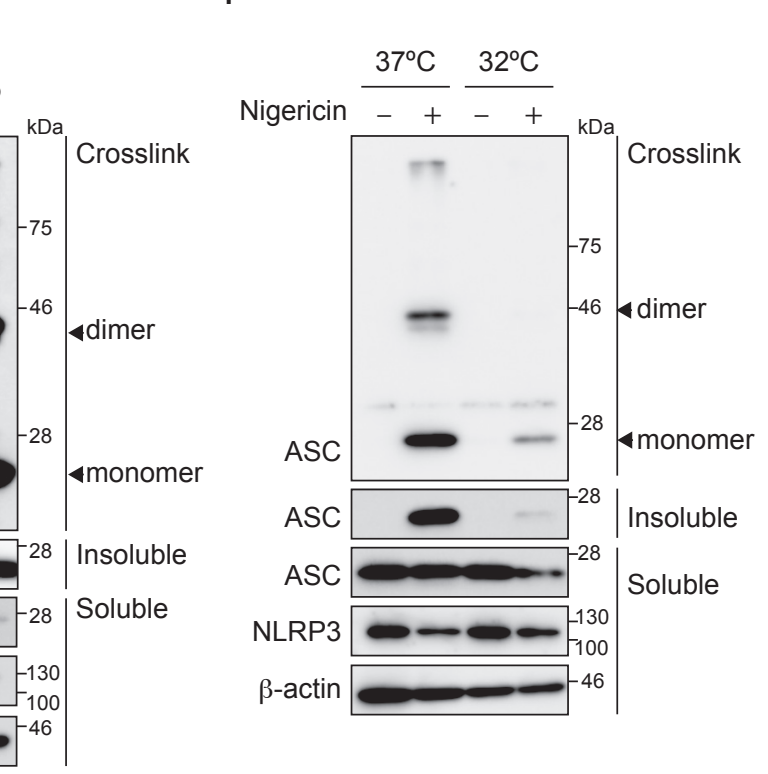

$\mathrm{H}$
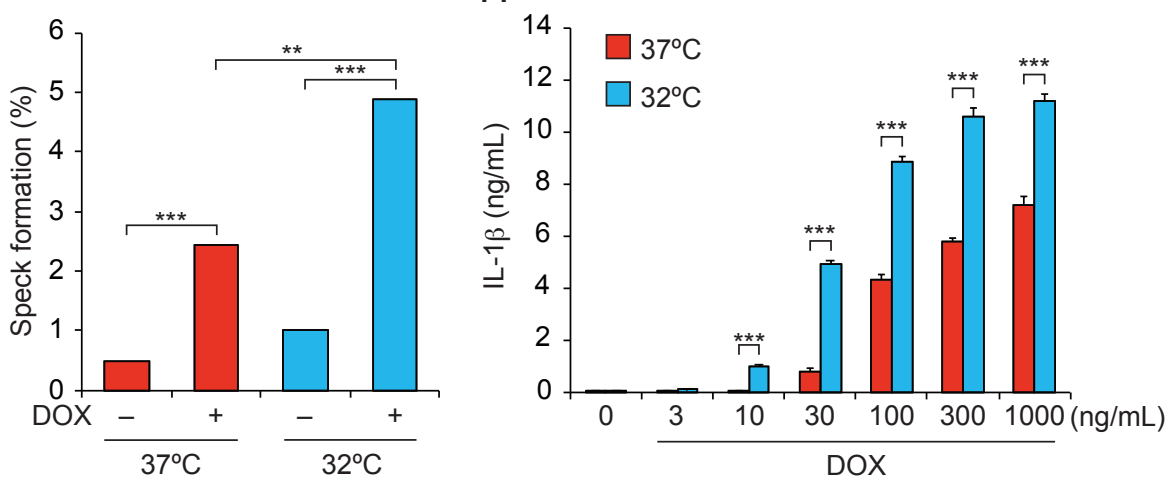

Figure 3. Aggregates formed by CAPS-associated NLRP3 mutant are the scaffold for inflammasome activation (A-C) EF1-ASC-BFP/TRE-NLRP3-WT or L353P-mNeonGreen THP-1 cells were treated with DOX. (A) Localization of ASC and NLRP3 was analyzed by confocal microscopy. (B) The number of foci was counted. (C) The ASC speck number in NLRP3 foci was analyzed. (D and E) TRE-NLRP3-L353P-THP-1 cells were differentiated with PMA for $24 \mathrm{~h}$ and then treated with DOX $(30 \mathrm{ng} / \mathrm{mL})$ at $37^{\circ} \mathrm{C}$ or $32^{\circ} \mathrm{C}$ for $6 \mathrm{~h}$. (D) Triton X-soluble and -insoluble fractions were analyzed by Western blot. (E) Oligomerized ASC in Triton X-insoluble fractions was crosslinked with BS3 and analyzed by Western blot. (F) Differentiated TRE-NLRP3-L353P-THP-1 cells were treated with nigericin at $37^{\circ} \mathrm{C}$ or $32^{\circ} \mathrm{C}$ for $6 \mathrm{~h}$. Triton X-insoluble fractions were crosslinked with BS3 and analyzed by Western blot. (G) EF-1-ASC-GFP/TRE-NLRP3-L353P-THP-1 cells were differentiated with PMA for $24 \mathrm{~h}$ and then treated with $\mathrm{DOX}(30 \mathrm{ng} / \mathrm{mL})$ at $37^{\circ} \mathrm{C}$ or $32^{\circ} \mathrm{C}$ for $6 \mathrm{~h}$. Representative images by confocal microscopy and the number of nuclei and specks were counted. (H) Differentiated TRE-NLRP3-L353P-THP-1 cells were treated with DOX at $37^{\circ} \mathrm{C}$ or $32^{\circ} \mathrm{C}$ for $6 \mathrm{~h}$. The IL-1 $\beta$ levels in the supernatants were assessed by ELISA $(n=3)$. $(\mathrm{B}, \mathrm{C}$ and $\mathrm{H})$ Data are expressed as the mean $\pm \mathrm{SD}$. ${ }^{*} P<0.05$, ${ }^{* *} P<0.01$, ${ }^{* *} P<0.005$ as determined by $(\mathrm{B}, \mathrm{C}$, and $\mathrm{H})$ two-way ANOVA with a post hoc test or $(G)$ Fisher' s exact test with the Holm correction. Data are representative of two or three independent experiments. 
A

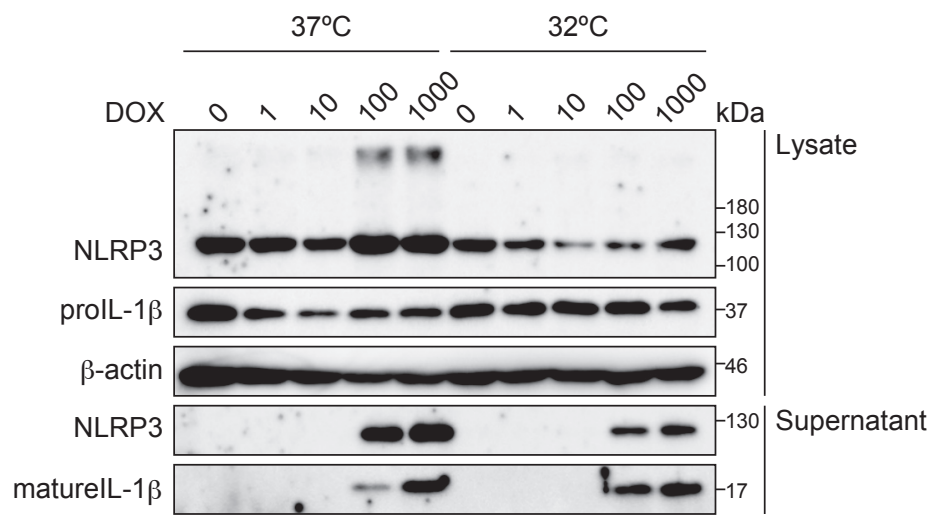

B

$37^{\circ} \mathrm{C} \quad 32^{\circ} \mathrm{C}$

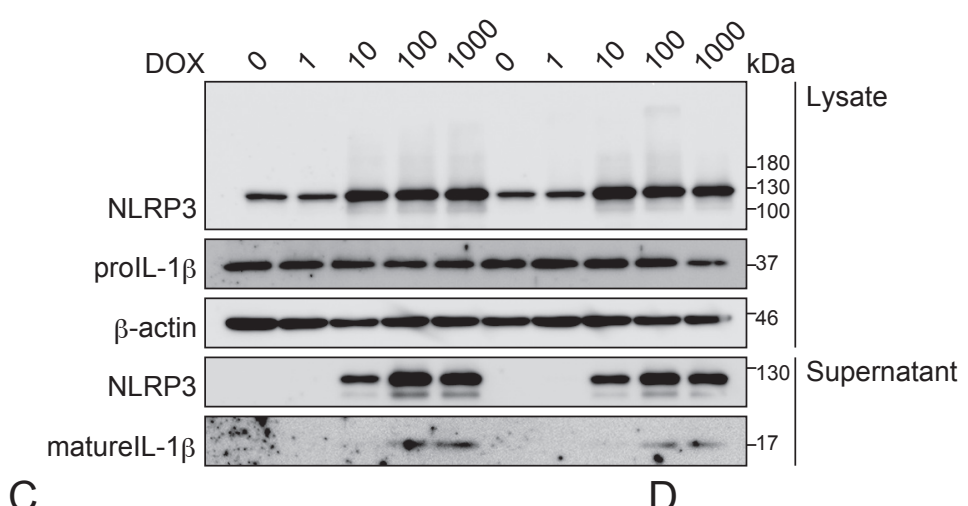

C
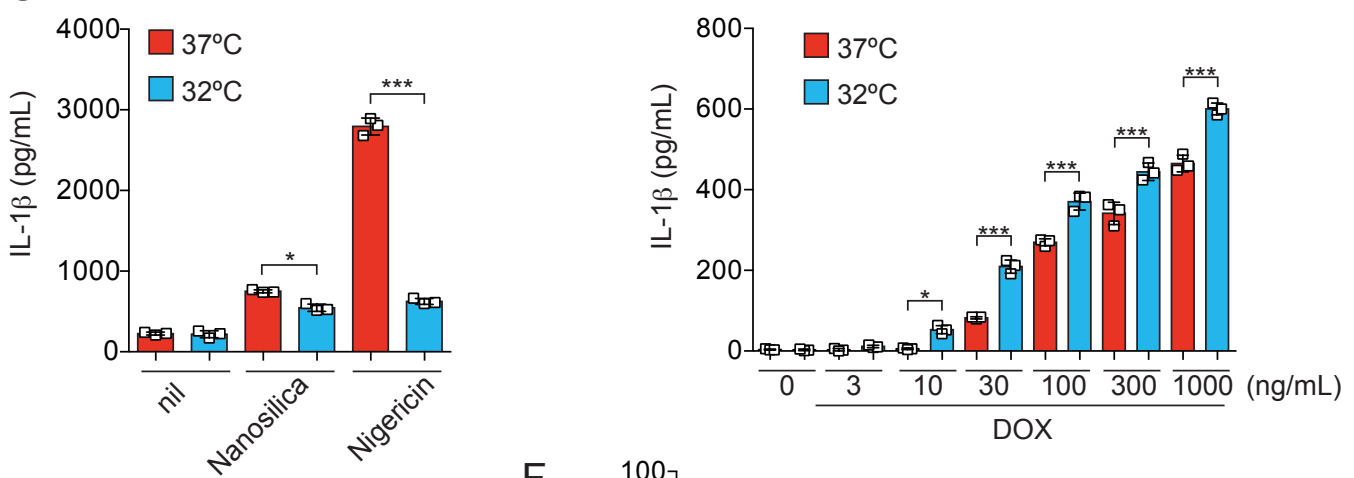

$E$
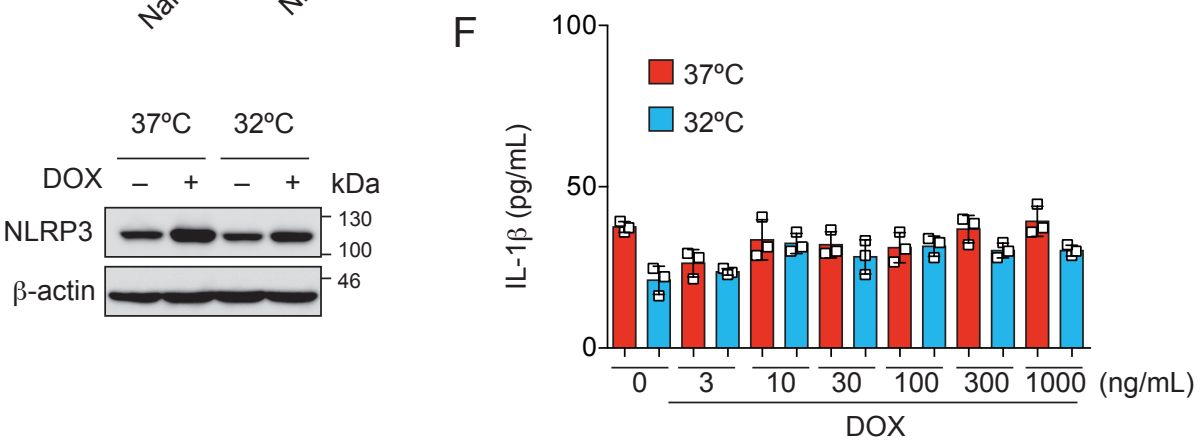

Figure 3 - figure supplement 1. Cold exposure enhances IL-1 $\beta$ release in NLRP3 FCAS mutant-expressing cells (A) TRE-NLRP3-L353P-or (B, D) NLRP3-D303N- or (E, F) NLRP3WT-THP-1 cells were differentiated with PMA for $24 \mathrm{~h}$ and then treated with DOX at $37^{\circ} \mathrm{C}$ or $32^{\circ} \mathrm{C}$ for $6 \mathrm{~h}$. (C) Differentiated TRE-NLRP3-L353P-THP-1 cells were treated with 5 $\mu \mathrm{M}$ nigericin or nanosilica $(30 \mu \mathrm{g} / \mathrm{mL})$ at $37^{\circ} \mathrm{C}$ or $32^{\circ} \mathrm{C}$ for $6 \mathrm{~h}$. (A, B, E) Lysates and supernatants were analyzed by western blot. (C, D, F) The levels of IL-1 $\beta$ in the supernatants were assessed by ELISA $(n=3)$. Data are expressed as the mean \pm SD. ${ }^{*} P<0.05,{ }^{* *} P<0.01,{ }^{* * *} P<0.005$ as determined by two-way ANOVA with a post hoc test. Data are representative of two independent experiments. 
L353P mutant-induced IL-1 $\beta$ release (Figure 4-figure supplement 2A and B). On the other hand, EGTA, a chelator of $\mathrm{Ca}^{2+}$, inhibited NLRP3-L353P mutant-induced IL-1 $\beta$ release (Figure 4A, Figure 4-figure supplement 2A and C). Moreover, decreased IL-1 $\beta$ release by NLRP3-L353P mutant under $\mathrm{Ca}^{2+}$-depleted conditions was restored by $\mathrm{Ca}^{2+}$ supplementation at $32^{\circ} \mathrm{C}$ (Figure 4B). Next, we assessed whether deprivation or supplementation of $\mathrm{Ca}^{2+}$ alters ASC oligomerization. $\mathrm{Ca}^{2+}$ deprivation by EGTA attenuated NLRP3-L353P-induced ASC oligomerization, whereas reduced ASC oligomerization in $\mathrm{Ca}^{2+}$-depleted conditions was restored by $\mathrm{Ca}^{2+}$ supplementation (Figure $4 \mathrm{C}$ and Figure 4 -figure supplement 2D). The requirement of $\mathrm{Ca}^{2+}$ for inflammasome assembly was also confirmed by the use of ASC-GFP reporter cells (Figure 4D and Figure 4-figure supplement 2E). The effect of $\mathrm{Ca}^{2+}$ on NLRP3 aggregation was analyzed using NLRP3-mNeonGreen reporter cells. Cryo-sensitive aggregation of NLRP3-L353P was decreased by $\mathrm{Ca}^{2+}$-depletion (Figure 4E and F). A similar dependency on $\mathrm{Ca}^{2+}$ was also detected in the CINCA-associated NLRP3-D303N mutant (Figure 4-figure supplement 3A). Moreover, DOX-induced NLRP3-L353P aggregation and ASC speck formation were attenuated by $\mathrm{Ca}^{2+}$-depletion (Figure $4 \mathrm{G}$ and $\mathrm{H}$ ). These results suggest that $\mathrm{Ca}^{2+}$ is an indispensable regulator of the aggregation of CAPS-associated NLRP3 mutants and subsequent activation of NLRP3 inflammasome.

\section{$\mathrm{Ca}^{2+}$ influx is provoked during mutated NLRP3-mediated inflammasome assembly}

To further investigate the role of $\mathrm{Ca}^{2+}$ in mutated NLRP3-mediated inflammasome activation, we monitored changes in $\mathrm{Ca}^{2+}$ levels using Fluo-8, a fluorescent $\mathrm{Ca}^{2+}$ indicator. After DOX-mediated induction of NLRP3-L353P, $\mathrm{Ca}^{2+}$ increase was clearly detected (Figure 5A-C). This increased intracellular $\mathrm{Ca}^{2+}$ is due to influx because $\mathrm{Ca}^{2+}$ increase was not observed in the absence of extracellular $\mathrm{Ca}^{2+}$ (Figure 5D-F, Video 1). The increased $\mathrm{Ca}^{2+}$ levels were not provoked by membrane rupture because $\mathrm{Ca}^{2+}$ influx occurred prior to the release of cytosolic content as indicated by Kusabira orange or membrane permeabilization as indicated by SYTOX (Figure 5-figure supplement 1A -D). Notably, inflammasome assembly monitored by ASC$\mathrm{BFP}$ and $\mathrm{Ca}^{2+}$ increase occurred coincidentally (Figure 5G-I). The size of ASC speck increased 
bioRxiv preprint doi: https://doi.org/10.1101/2021.10.05.463273; this version posted October 29, 2021. The copyright holder for this preprint (which was not certified by peer review) is the author/funder, who has granted bioRxiv a license to display the preprint in perpetuity. It is made available under aCC-BY-NC-ND 4.0 International license.

A

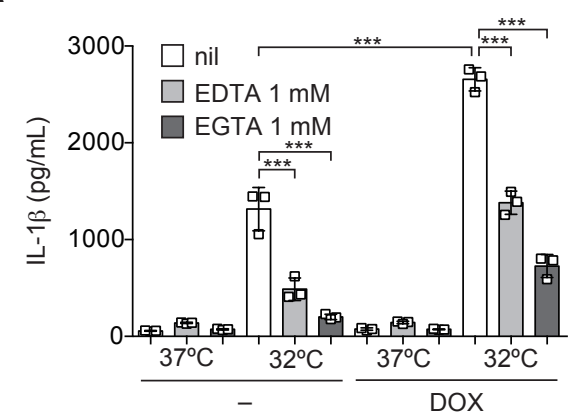

B

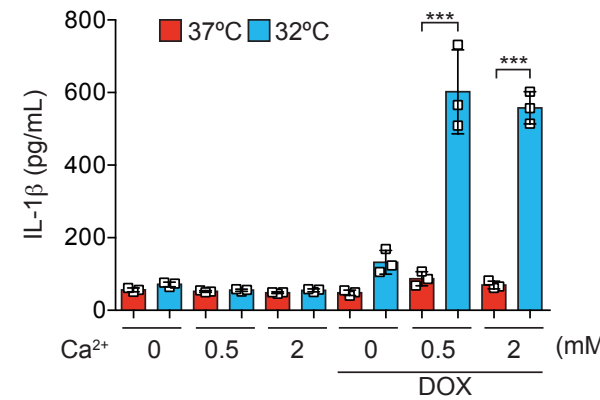

$\mathrm{E}$

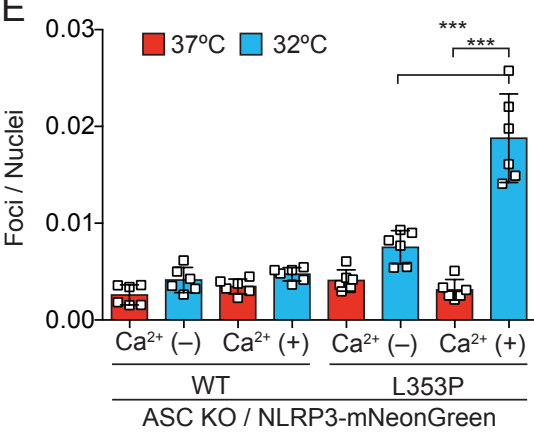

C

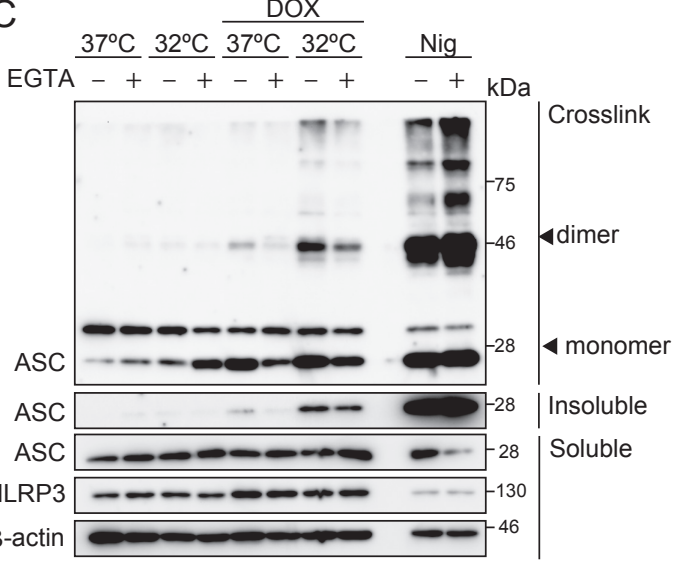

G

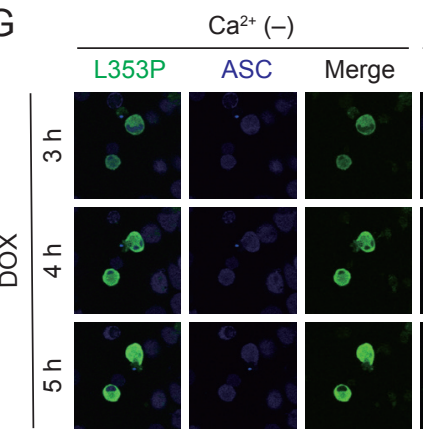

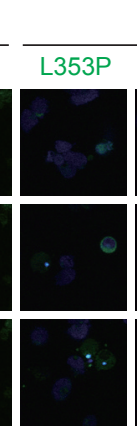

$F$

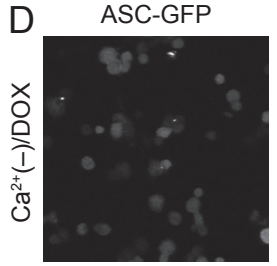

$\times$
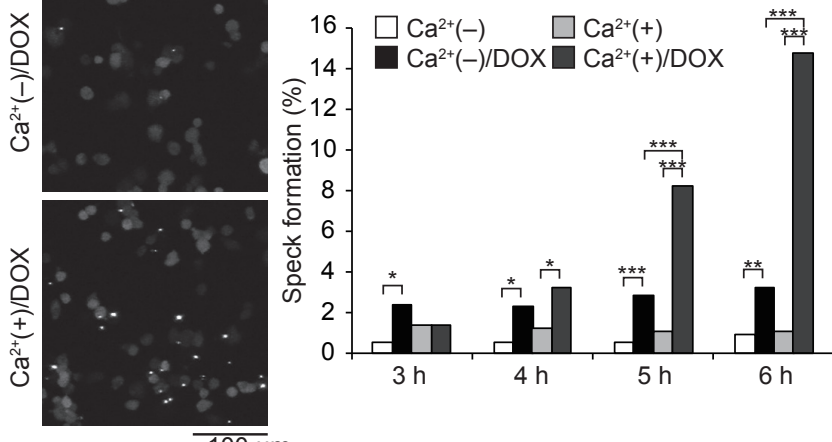

$\overline{100 \mu \mathrm{m}}$

ASC KO / NLRP3-L353P-mNeonGreen

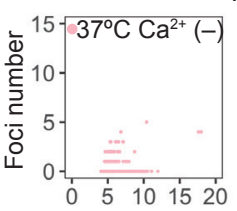

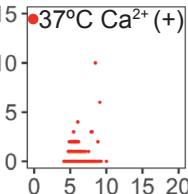

Relative fluorescence intensity

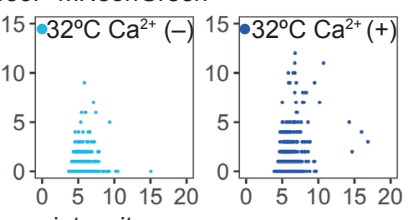

$\mathrm{H}$

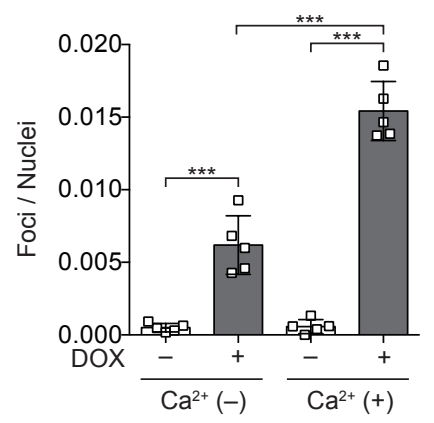

Figure 4. $\mathrm{Ca}^{2+}$ is required for CAPS-associated NLRP3 mutant-mediated inflammasome assembly

(A-C) Differentiated TRE-NLRP3-L353P-THP-1 cells were pretreated with indicated conditions, and then treated with DOX $(30 \mathrm{ng} / \mathrm{mL})$ at $37^{\circ} \mathrm{C}$ or $32^{\circ} \mathrm{C}$ for $6 \mathrm{~h}$. (A and B) The IL-1 $\beta$ levels in the supernatants were assessed by ELISA $(n=3)$. (C) Oligomerized ASC in Triton X-insoluble fractions was crosslinked with BS3 and analyzed by Western blot. (D) EF1-ASC-GFP/TRE-NLRP3-L353P-THP-1 cells were pretreated with $\mathrm{Ca}^{2+}$-depleted or -supplemented media and then treated with DOX $(30 \mathrm{ng} / \mathrm{mL})$ at $37^{\circ} \mathrm{C}$. ASC speck formation was analyzed by confocal microscopy. (E and F) EF1-NLRP3-WT- or L353P-mNeonGreen-THP-1 cells were cultured at $37^{\circ} \mathrm{C}$ or $32^{\circ} \mathrm{C}$ for $24 \mathrm{~h}$ in $\mathrm{Ca}^{2+}$-depleted or -supplemented media. The number of foci and fluorescent intensity were analyzed by high content analysis. $(G$ and $H)$ Differentiated EF1-ASC-BFP/TRE-NLRP3-L353P-mNeonGreen- THP-1 cells were pretreated with $\mathrm{Ca}^{2+}$-depleted or -supplemented media and then treated with DOX $(30 \mathrm{ng} / \mathrm{mL})$ at $37^{\circ} \mathrm{C}$. (G) Representative images by confocal microscopy $(\mathrm{H})$ The number of foci was analyzed by high content analysis. (A, B, E, and H) Data are expressed as the mean \pm SD. ${ }^{*} P<$ $0.05,{ }^{* *} P<0.01$, ${ }^{* *} P<0.005$ as determined by $(\mathrm{A}, \mathrm{B}, \mathrm{E}$, and $\mathrm{H})$ two-way ANOVA with a post hoc test or (D) Fisher' s exact test with the Holm correction. Data are representative of two or three independent experiments. 
A

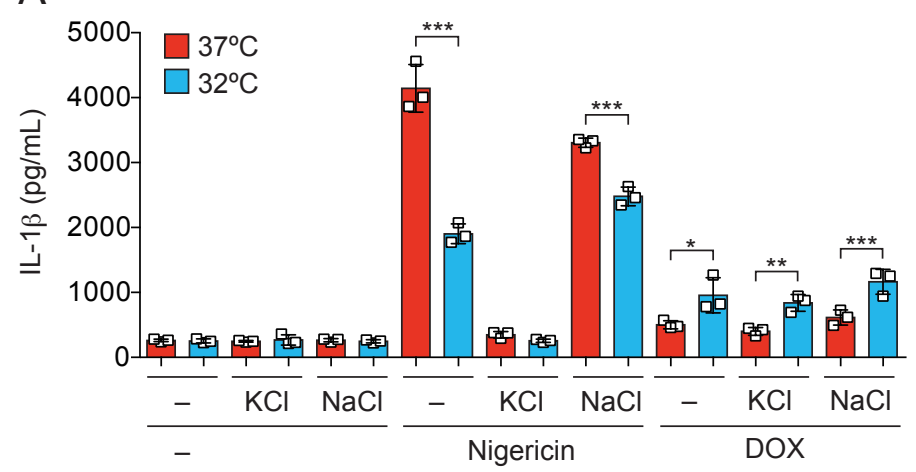

B

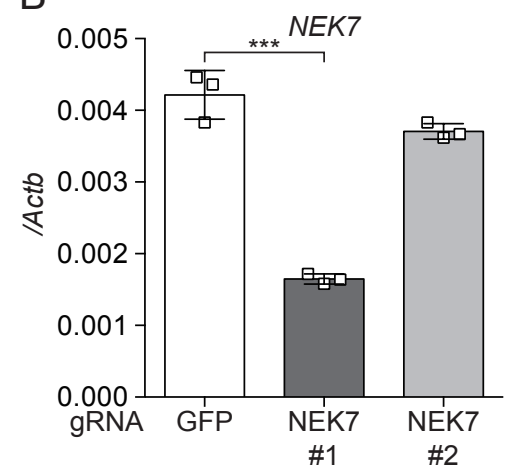

C

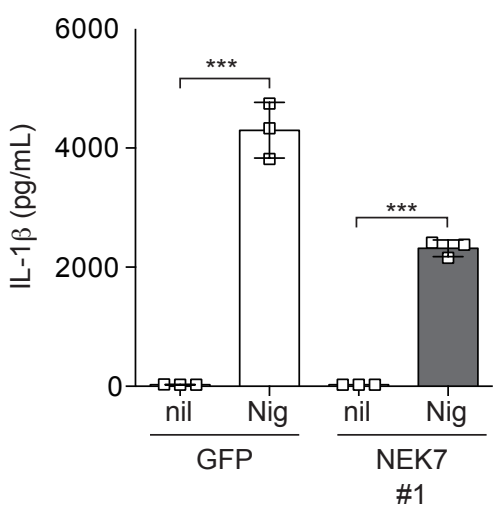

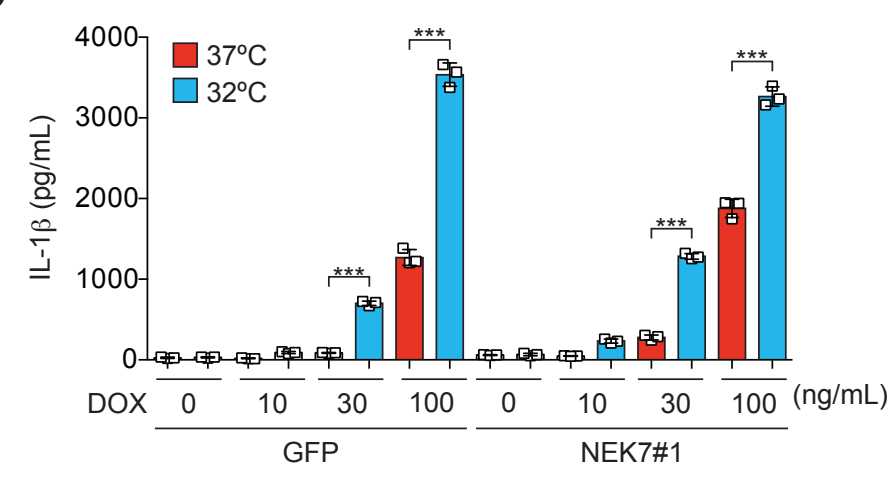

Figure 4 - figure supplement $1 . \mathrm{K}^{+}$efflux is dispensable for inflammasome activation induced by NLRP3 FCAS-mutant

(A) Differentiated TRE-NLRP3-L353P-THP-1 cells were pretreated with the indicated dose of $\mathrm{KCl}$ or $\mathrm{NaCl}$ and then treated with DOX $(30 \mathrm{ng} / \mathrm{mL})$ at $37^{\circ} \mathrm{C}$ or $32^{\circ} \mathrm{C}$ for $6 \mathrm{~h}$. (B-D) NEK7-mutated TRE-NLRP3-L353P-THP-1 cells were differentiated with PMA for $24 \mathrm{~h}$. (B) mRNA expression of NEK7 was analyzed by qPCR $(n=3)$. The differentiated NEK7-mutated NLRP3-L353P-THP-1 cells were treated with (C) nigericin or (D) DOX (30 ng/mL) at $37^{\circ} \mathrm{C}$ or $32^{\circ} \mathrm{C}$ for $6 \mathrm{~h}$. The levels of IL-1 $\beta$ in the supernatants were assessed by ELISA $(n=3)$. The levels of IL-1 $\beta$ in the supernatants were assessed by ELISA $(n=3)$. (A-D) Data are expressed as the mean \pm SD. ${ }^{*} P<0.05$, ${ }^{* *} P<0.01$, ${ }^{* *} P<0.005$ as determined by two-way ANOVA with a post hoc test. Data are representative of two independent experiments. 

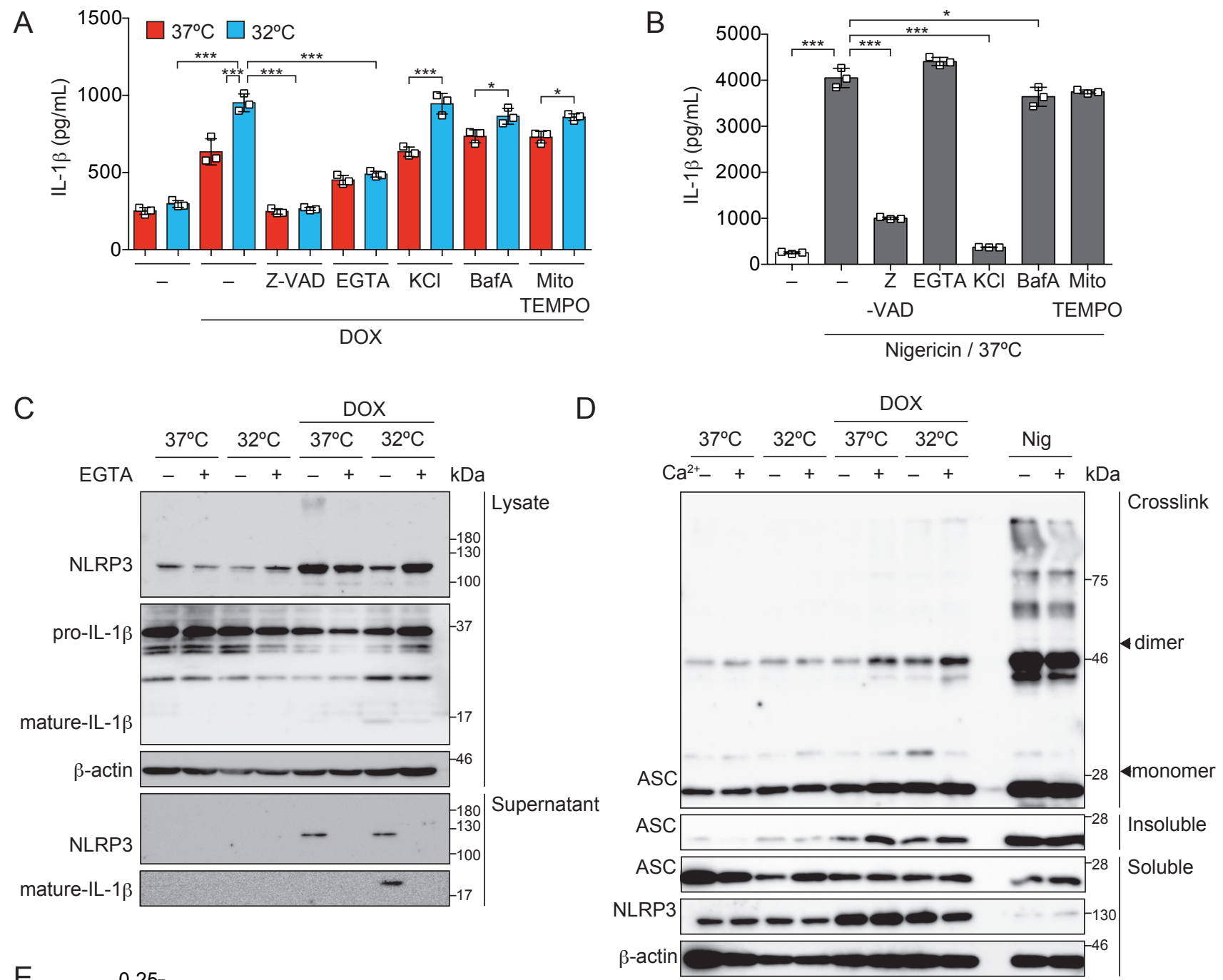

$E$

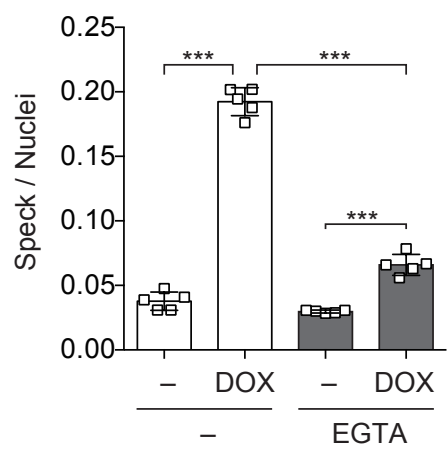

Figure 4 - figure supplement 2. $\mathrm{Ca}^{2+}$ is necessary for inflammasome activation induced by mutated NLRP3 (A and B) Differentiated TRE-NLRP3-L353P-THP-1 cells were pretreated with the indicated inhibitors and then treated with DOX $(30 \mathrm{ng} / \mathrm{mL})$ or nigericin $(5 \mu \mathrm{M})$ at $37^{\circ} \mathrm{C}$ or $32^{\circ} \mathrm{C}$ for $6 \mathrm{~h}$. The levels of IL-1 $\beta$ in the supernatants were assessed by ELISA ( $n=3)$. (C) Differentiated TRE-NLRP3-L353P-THP-1 cells were pretreated with EGTA and then treated with DOX (30 $\mathrm{ng} / \mathrm{mL}$ ) at $37^{\circ} \mathrm{C}$ or $32^{\circ} \mathrm{C}$ for $6 \mathrm{~h}$. Lysates and supernatants were analyzed by western blot. (D) Differentiated

TRE-NLRP3-L353P-THP-1 cells were pretreated with $\mathrm{Ca}^{2+}$-depleted or -supplemented media and then treated with DOX $\left(30 \mathrm{ng} / \mathrm{mL}\right.$ ) at $37^{\circ} \mathrm{C}$ or $32^{\circ} \mathrm{C}$ for $6 \mathrm{~h}$. Oligomerized ASC in Triton X-insoluble fractions was crosslinked by BS3 and analyzed by western blot. (E) EF1-ASC-GFP/TRE-NLRP3-L353P-THP-1 cells were pretreated with EGTA and then treated with DOX $(30 \mathrm{ng} / \mathrm{mL})$ at $37^{\circ} \mathrm{C}$. The formation of ASC-speck was analyzed by high content analysis. (A, B and E) Data are expressed as the mean $\pm \mathrm{SD} .{ }^{*} P<0.05,{ }^{* *} P<0.01,{ }^{* *} P<0.005$ as determined by two-way ANOVA with a post hoc test. Data are representative of two or three independent experiments. 
bioRxiv preprint doi: https://doi.org/10.1101/2021.10.05.463273; this version posted October 29, 2021. The copyright holder for this preprint (which was not certified by peer review) is the author/funder, who has granted bioRxiv a license to display the preprint in perpetuity. It is made available under aCC-BY-NC-ND 4.0 International license.

A
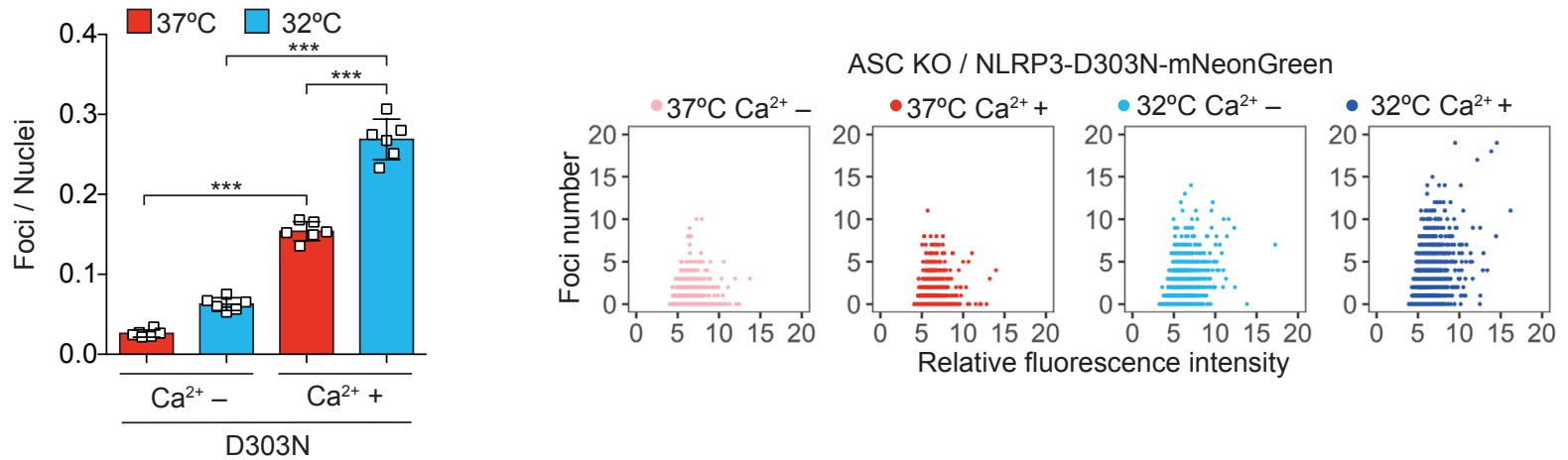

Figure 4 - figure supplement 3. $\mathrm{Ca}^{2+}$ is necessary for aggregation of NLRP3-D303N-mutant

(A) EF1-NLRP3-D303N-mNeonGreen-THP-1 cells were cultured at $37^{\circ} \mathrm{C}$ or $32^{\circ} \mathrm{C}$ for $24 \mathrm{~h}$ in $\mathrm{Ca}^{2+}$-depleted or -supplemented media. The number of foci and fluorescent intensity were analyzed by high content analysis. Data are expressed as the mean $\pm \mathrm{SD}$. ${ }^{* *} P<0.005$ as determined by two-way ANOVA with a post hoc test. Data are representative of three independent experiments. 
with the increase in $\mathrm{Ca}^{2+}$. These results indicate that $\mathrm{Ca}^{2+}$ influx occurs during inflammasome activation induced by NLRP3 mutants.

\section{Caspase-1 inhibition prevents mutated NLRP3-mediated inflammasome assembly}

Recent studies have suggested that caspase-mediated pore formation by GSDMD causes the influx of $\mathrm{Ca}^{2+}$ (de Vasconcelos et al., 2019). We postulated that caspase-dependent $\mathrm{Ca}^{2+}$ influx might enhance inflammasome assembly. To investigate the effect of caspase-1 inhibition on $\mathrm{Ca}^{2+}$ influx, cells were treated with VX-765, a caspase-1 inhibitor, prior to DOXmediated NLRP3-L353P induction. Indeed, VX-765 canceled $\mathrm{Ca}^{2+}$ influx (Figure 6A-C, Video 2, Figure 6-figure supplement 1A and B) and inhibited ASC oligomerization and speck formation induced by NLRP3-L353P (Figure 6D and E). In accordance with reduced inflammasome assembly, VX-765 also prevented NLRP3-L353P-induced IL-1 $\beta$ release (Figure 6F). These results indicate that caspase-1 activation induced by NLRP3 mutants promotes incremental inflammasome assembly by regulating $\mathrm{Ca}^{2+}$ influx. On the other hand, MCC950 (Coll et al., 2015), a potent NLRP3 inhibitor, failed to prevent ASC speck formation and IL-1 $\beta$ release induced by NLRP3-L353P, although MCC950 efficiently inhibited nigericin-induced IL-1 $\beta$ release (Figure 6-figure supplement $2 \mathrm{~A}-\mathrm{C}$ ). These results suggest that caspase-1 inhibition could be a potential therapeutic target of CAPS.

\section{Discussion}

In the present study, we demonstrated that CAPS-associated NLRP3 mutants form cryo-sensitive foci intracellularly. These foci are aggregates that function as a scaffold for inflammasome activation. Consistent with this finding, inflammasome assembly and subsequent IL-1 $\beta$ release induced by CAPS-associated NLRP3 mutants are cryo-sensitive. The aggregation of CAPS-associated NLRP3 mutants is regulated by intracellular $\mathrm{Ca}^{2+}$ levels. Furthermore, caspase- 1 inhibition prevents $\mathrm{Ca}^{2+}$ influx and inflammasome assembly induced by CAPS-associated NLRP3 mutants (Figure 7). These findings provide new insights into the molecular mechanisms of inflammasome activation in CAPS. 


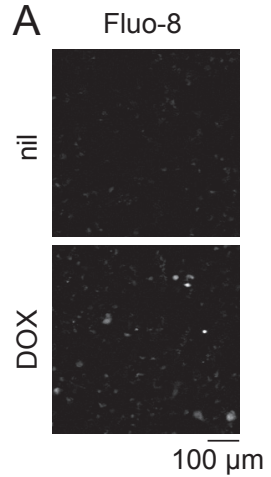

$\mathrm{D}$

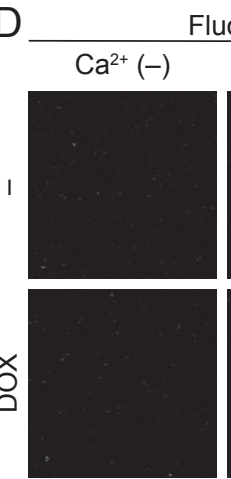

G

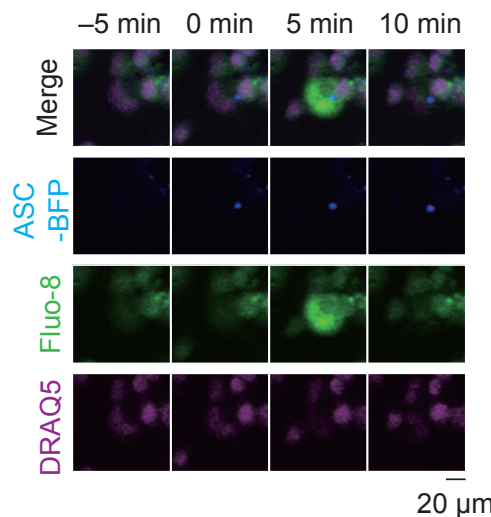

$E$

$20 \mu \mathrm{m}$
B

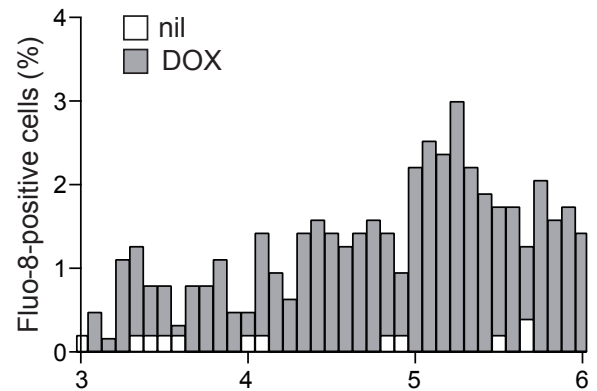

(h)

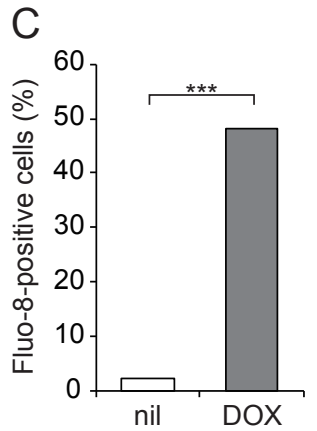

$\mathrm{F}$
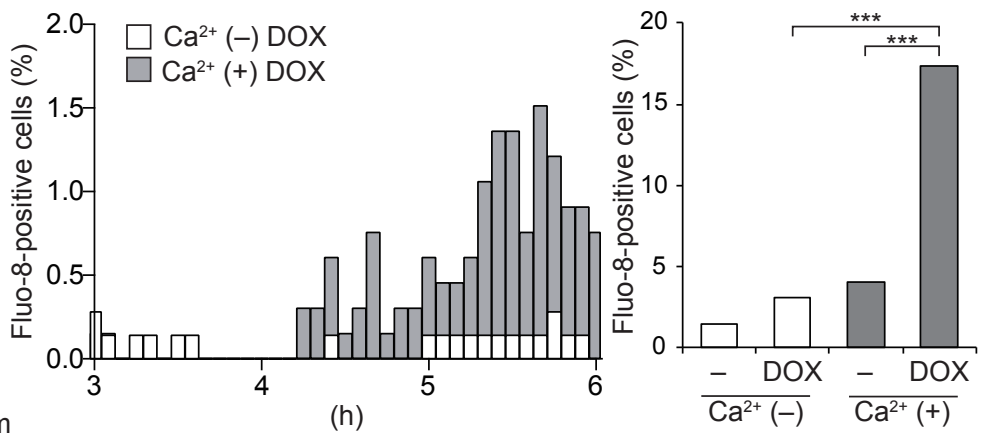

$\mathrm{H}$

I
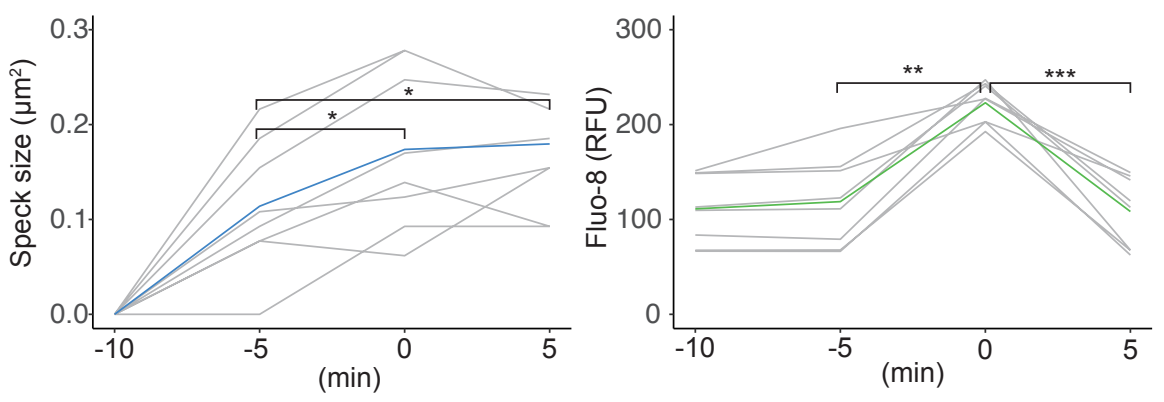

Figure 5. $\mathrm{Ca}^{2+}$ influx is provoked during mutated NLRP3-mediated inflammasome assembly

(A-C) Differentiated TRE-NLRP3-L353P-THP-1 cells were loaded with $4 \mu \mathrm{M}$ Fluo-8 for $1 \mathrm{~h}$ and treated with DOX (30 $\mathrm{ng} / \mathrm{mL}$ ) at $37^{\circ} \mathrm{C}$ for $6 \mathrm{~h}$. The images were recorded by confocal microscopy at 5-min intervals from $3 \mathrm{~h}$ to $6 \mathrm{~h}$. (A)

Representative temporal subtraction images. (B) The frequency of intracellular $\mathrm{Ca}^{2+}$ increase at each time point. (C) The cumulative number of Fluo-8-positive cells. (D-F) Differentiated TRE-NLRP3-L353P-THP-1 cells were loaded with $4 \mu \mathrm{M}$ Fluo-8 for $1 \mathrm{~h}$ and treated with DOX $(30 \mathrm{ng} / \mathrm{mL})$ at $37^{\circ} \mathrm{C}$ for $6 \mathrm{~h}$ in $\mathrm{Ca}^{2+}$-depleted or -supplemented media. The images were recorded by confocal microscopy at 5 -min intervals from $3 \mathrm{~h}$ to $6 \mathrm{~h}$. (D) Representative temporal subtraction images. (E) The frequency of intracellular $\mathrm{Ca}^{2+}$ increase at each time point. (F) The cumulative number of Fluo-8-positive cells. (G-I) Differentiated EF1-ASC-BFP/TRE-NLRP3-L353P-THP-1 cells were loaded with $4 \mu \mathrm{M}$ Fluo-8 for $1 \mathrm{~h}$ and treated with DOX $(30 \mathrm{ng} / \mathrm{mL})$ at $37^{\circ} \mathrm{C}$. The images were recorded at 5-min intervals. (G) Representative images of the cells with increased Fluo-8 signals. $(\mathrm{H})$ The ASC-BFP speck size (I) and fluorescent intensity of Fluo-8 in were analyzed. The peak time point of Fluo-8 signals was defined as $0 \mathrm{~min}$. $(\mathrm{H})$ The blue line and the $(\mathrm{I})$ green line represent mean values and the gray line represents each measurement. ${ }^{*} P<0.05$, ${ }^{* *} P<0.01$, ${ }^{* *} P<0.005$ as determined by $(\mathrm{C}$ and $\mathrm{F})$ Fisher' s exact test with the Holm correction or $(\mathrm{H}$ and $\mathrm{I})$ repeated one-way ANOVA with a post hoc test. (A-G) Data are representative of three independent experiments. ( $\mathrm{H}$ and $\mathrm{I})$ Data are from three independent live-cell imaging. 
bioRxiv preprint doi: https://doi.org/10.1101/2021.10.05.463273; this version posted October 29, 2021. The copyright holder for this preprint (which was not certified by peer review) is the author/funder, who has granted bioRxiv a license to display the preprint in perpetuity. It is made available under aCC-BY-NC-ND 4.0 International license.

Video 1 . Caspase activity is required for $\mathrm{Ca}^{2+}$ influx induced by mutated NLRP3

Differentiated TRE-NLRP3-L353P-THP-1 cells were loaded with $4 \mu \mathrm{M}$ Fluo-8 for $1 \mathrm{~h}$ and treated with DOX (30 ng/mL) at $37^{\circ} \mathrm{C}$ for $6 \mathrm{~h}$ in $\mathrm{Ca}^{2+}$-depleted or -supplemented media. The images were recorded by confocal microscopy at 5-min intervals from $3 \mathrm{~h}$ to $6 \mathrm{~h}$.

A

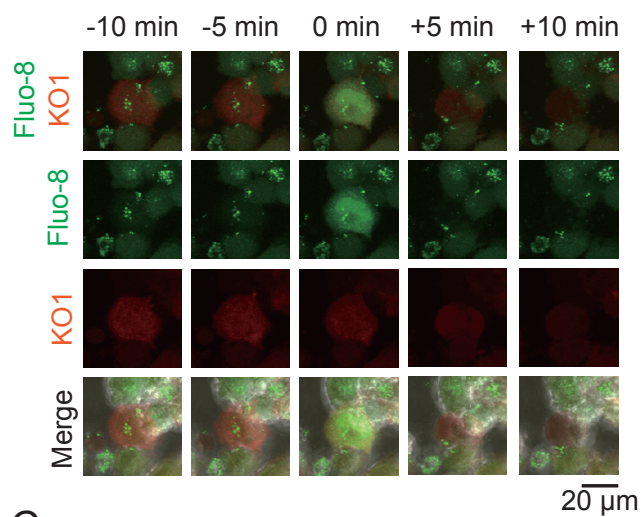

C

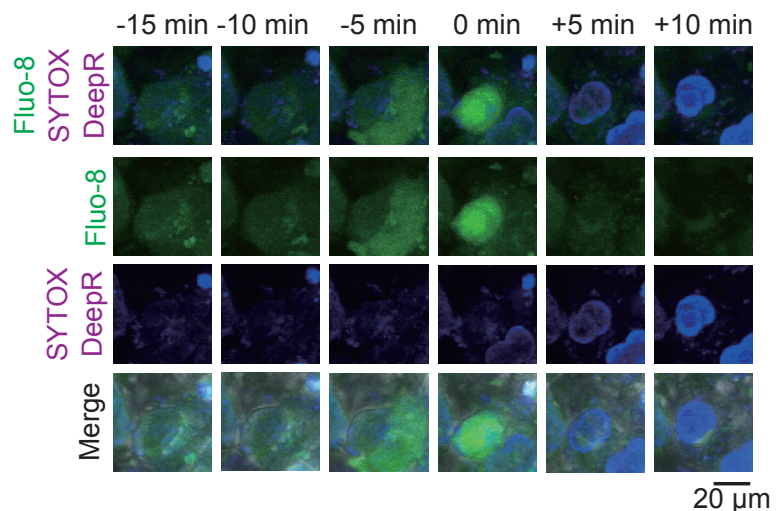

B

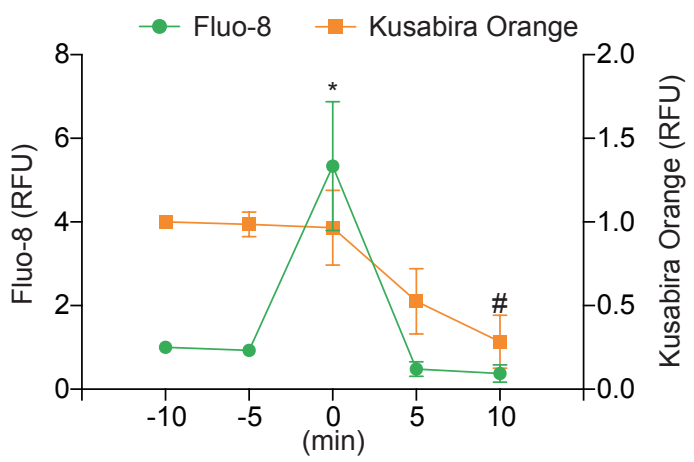

D

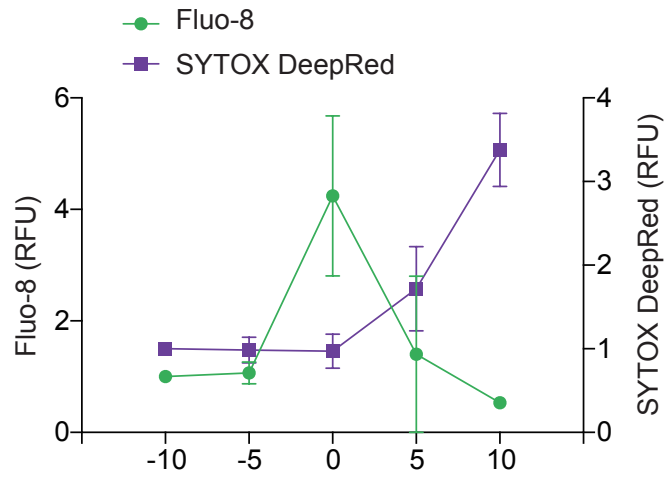

Figure 5 - figure supplement 1. Pyroptosis is induced by mutated NLRP3 after Ca2+ influx

(A and B) Differentiated TRE-NLRP3-L353P-THP-1 cells were loaded with $4 \mu \mathrm{M}$ Fluo-8 for $1 \mathrm{~h}$ and treated with doxycycline $\left(30 \mathrm{ng} / \mathrm{mL}\right.$ ) at $37^{\circ} \mathrm{C}$ for $6 \mathrm{~h}$. (A) Representative images of cells with increased Fluo-8 signal. (B) The relative fluorescent intensity of Fluo-8 and Kusabira Orange in cells with increased Fluo-8 signal was quantified $(n=10)$. $(C$ and $D)$ Differentiated TRE-NLRP3-L353P-THP-1 cells were loaded with $4 \mu \mathrm{M}$ Fluo-8 for $1 \mathrm{~h}$ and treated with DOX (30 ng/mL) at $37^{\circ} \mathrm{C}$ for $6 \mathrm{~h}$ in the presence of SYTOX DeepRed. (C) Representative images of cells with increased Fluo-8 signal. (D) The relative fluorescent intensity of Fluo-8 and SYTOX DeepRed in cells with increased Fluo-8 signal was quantified $(n=5)$. Data are expressed as the mean \pm SD. ${ }^{*} P<0.05$, as determined by repeated one-way ANOVA with a post hoc test. Data are analyzed from two independent time-lapse imaging. 
bioRxiv preprint doi: https://doi.org/10.1101/2021.10.05.463273; this version posted October 29, 2021. The copyright holder for this preprint (which was not certified by peer review) is the author/funder, who has granted bioRxiv a license to display the preprint in perpetuity. It is made available under aCC-BY-NC-ND 4.0 International license.

A

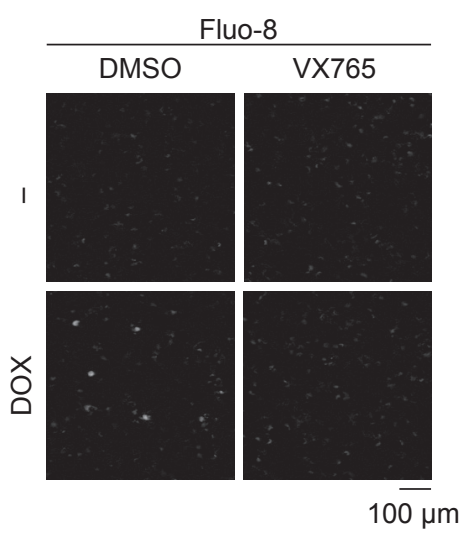

D

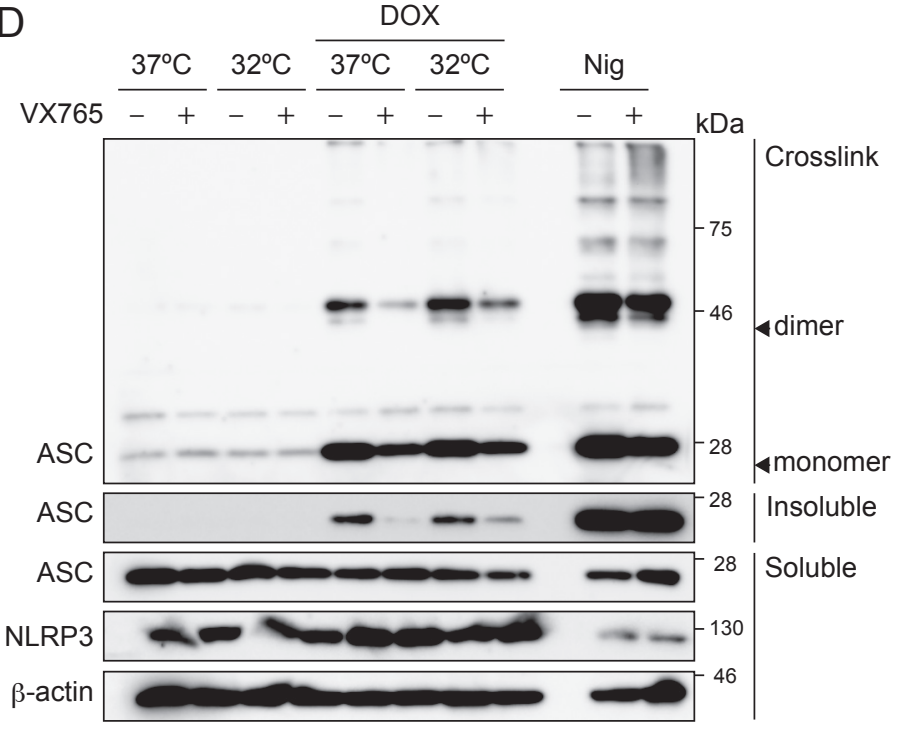

$\mathrm{F}$

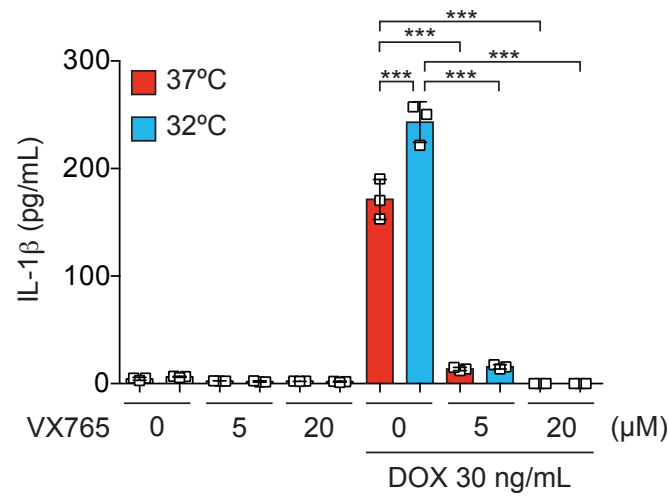

(h)

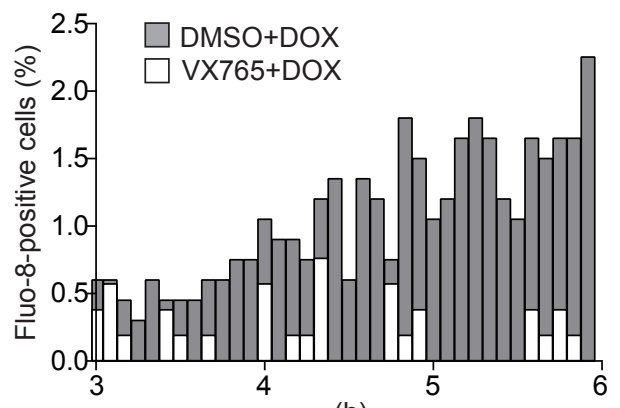

E
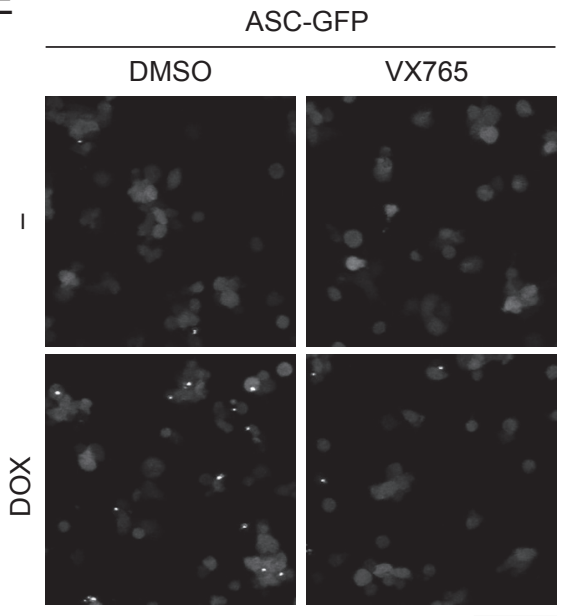

$100 \mu \mathrm{m}$

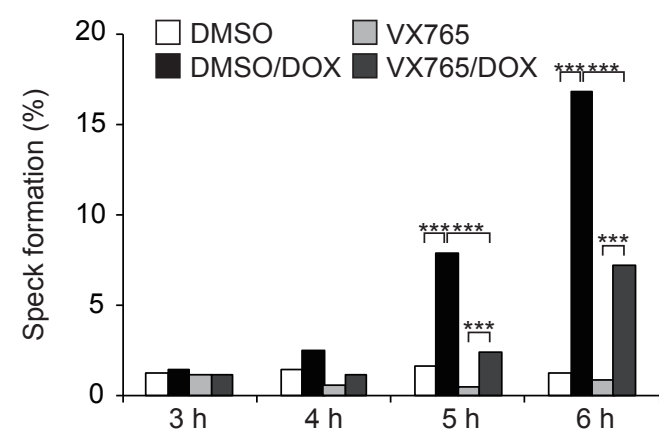

Figure 6. Caspase-1 inhibition prevents mutated NLRP3-mediated inflammasome assembly.

(A -C) Differentiated TRE-NLRP3-L353P-THP-1 cells were loaded with $4 \mu \mathrm{M}$ Fluo-8 for $1 \mathrm{~h}$ and were pretreated with VX-765 $(20 \mu \mathrm{M})$ for $30 \mathrm{~min}$. After DOX (30 ng/mL) treatment, the images were recorded at 5-min intervals from $3 \mathrm{~h}$ to $6 \mathrm{~h}$. (A) Representative temporal subtraction images. (B) The frequency of intracellular $\mathrm{Ca}^{2+}$ increase at each time point. (C) The cumulative number of Fluo-8-positive cells. (D-F) Differentiated TRE-NLRP3-L353P-THP-1 cells were pretreated with VX-765 $(20 \mu \mathrm{M})$ for 30 min and then treated with DOX $(30 \mathrm{ng} / \mathrm{mL})$ or nigericin $(5 \mu \mathrm{M})$ at $37^{\circ} \mathrm{C}$ or $32^{\circ} \mathrm{C}$. (D) Triton X-insoluble fractions were crosslinked with BS3 and analyzed by Western blot. $(F)$ The IL-1 $\beta$ levels in the supernatants were assessed by ELISA $(n=3)$. (E) EF1-ASC-GFP/TRE-NLRP3-L353P-THP-1 cells were pretreated with $20 \mu \mathrm{M} V \mathrm{VX}-765$ for 30 min and then treated with DOX $(30 \mathrm{ng} / \mathrm{mL})$ at $37^{\circ} \mathrm{C}$. ASC speck formation was analyzed by confocal microscopy. (F) Data are expressed as the mean $\pm \mathrm{SD}$. ${ }^{*} P<0.05,{ }^{* *} P<0.01$, ${ }^{* * *} P<0.005$ as determined by $(\mathrm{C}$ and $\mathrm{E})$ Fisher' $\mathrm{s}$ exact test with the Holm correction or (F) two-way ANOVA with a post hoc test. Data are representative of two or three independent experiments. 
A

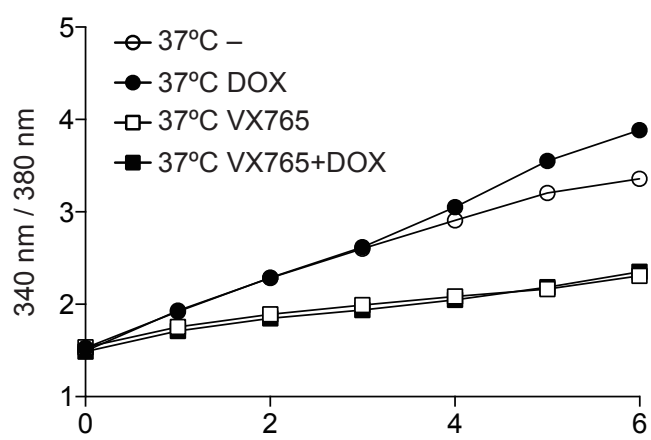

(h)
B

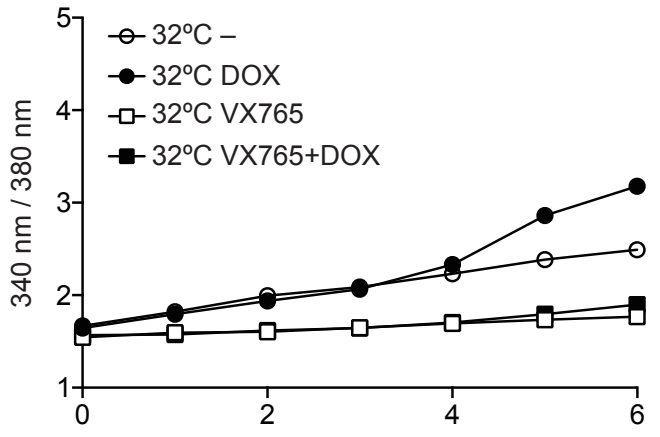

(h)

Figure 6 - figure supplement 1 . Caspase activity is required for $\mathrm{Ca}^{2+}$ influx induced by mutated NLRP3 (A and B) Differentiated TRE-NLRP3-L353P-THP-1 cells were loaded with $3 \mu \mathrm{M}$ Fura2 for $1 \mathrm{~h}$. Cells were pretreated $20 \mu \mathrm{M}$ VX765 for $30 \mathrm{~min}$ and then treated with $\mathrm{DOX}(30 \mathrm{ng} / \mathrm{mL})$ at $37^{\circ} \mathrm{C}$ or $32^{\circ} \mathrm{C}$ for $6 \mathrm{~h}$. Fluorescence $(A)$ at $37^{\circ} \mathrm{C}$ and $(B)$ at $32^{\circ} \mathrm{C}$ was measured at hourly interval $(n=6)$. Data are expressed as the mean $\pm S D$. Data are representative of two independent experiments.

Video 2 . Caspase activity is required for $\mathrm{Ca}^{2+}$ influx induced by mutated NLRP3

Differentiated TRE-NLRP3-L353P-THP-1 cells were loaded with $4 \mu \mathrm{M}$ Fluo-8 for $1 \mathrm{~h}$ and were pretreated with VX-765 (20 $\mu \mathrm{M})$ for $30 \mathrm{~min}$. After DOX (30 $\mathrm{ng} / \mathrm{mL})$ treatment, the images were recorded at 5 -min intervals from $3 \mathrm{~h}$ to $6 \mathrm{~h}$. 
A

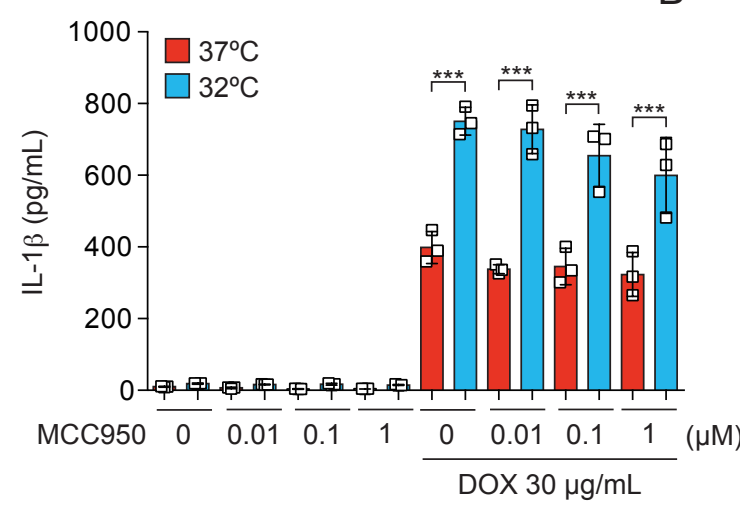

C

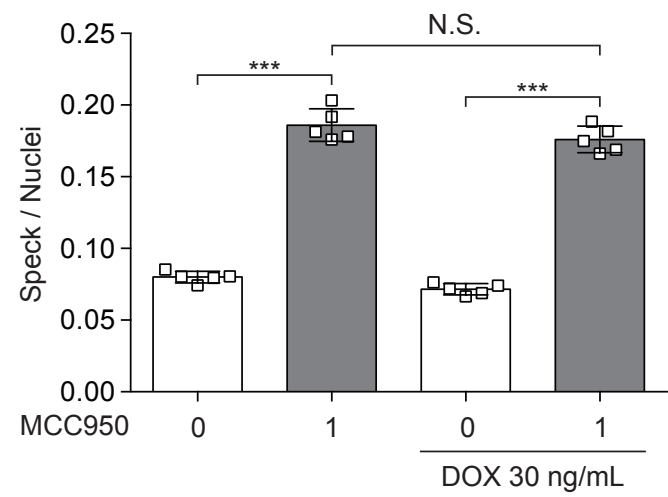

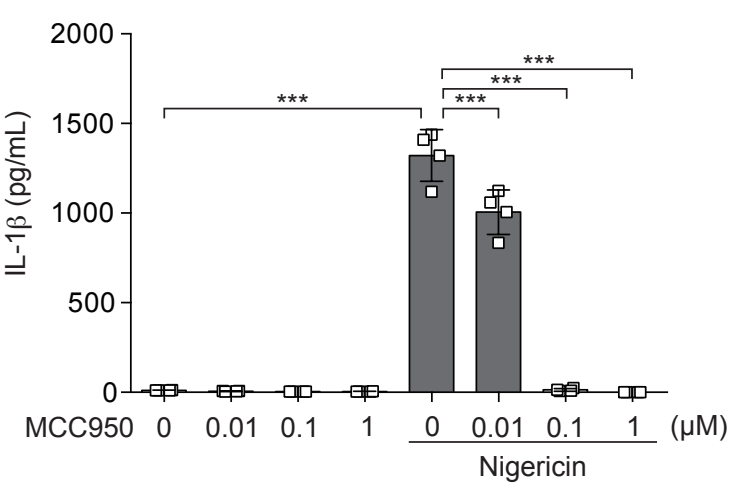

Figure 6 - figure supplement 2 . MCC950 failed to inhibit mutated NLRP3-induced inflammasome activation (A-B) Differentiated TRE-NLRP3-L353P-THP-1 cells were pretreated with MCC950 for 30 min and then treated with (A) DOX $(30 \mathrm{ng} / \mathrm{mL})$ or $(B)$ nigericin $(5 \mu \mathrm{M})$ at $37^{\circ} \mathrm{C}$ or $32^{\circ} \mathrm{C}$. The levels of IL-1 3 in the supernatants were determined by ELISA $(\mathrm{n}=3$ ). (C) EF1-ASC-GFP/TRE-NLRP3-L353P-THP-1 cells were pretreated with MCC950 and then treated with DOX (30 $\mathrm{ng} / \mathrm{mL}$ ) at $37^{\circ} \mathrm{C}$. The formation of ASC-speck was analyzed by high content analysis. Data are expressed as the mean \pm SD. ${ }^{* *} P<0.005$ as determined by one-way ANOVA with a post hoc test. Data are representative of two independent experiments. 
bioRxiv preprint doi: https://doi.org/10.1101/2021.10.05.463273; this version posted October 29, 2021. The copyright holder for this preprint (which was not certified by peer review) is the author/funder, who has granted bioRxiv a license to display the preprint in perpetuity. It is made available under aCC-BY-NC-ND 4.0 International license.

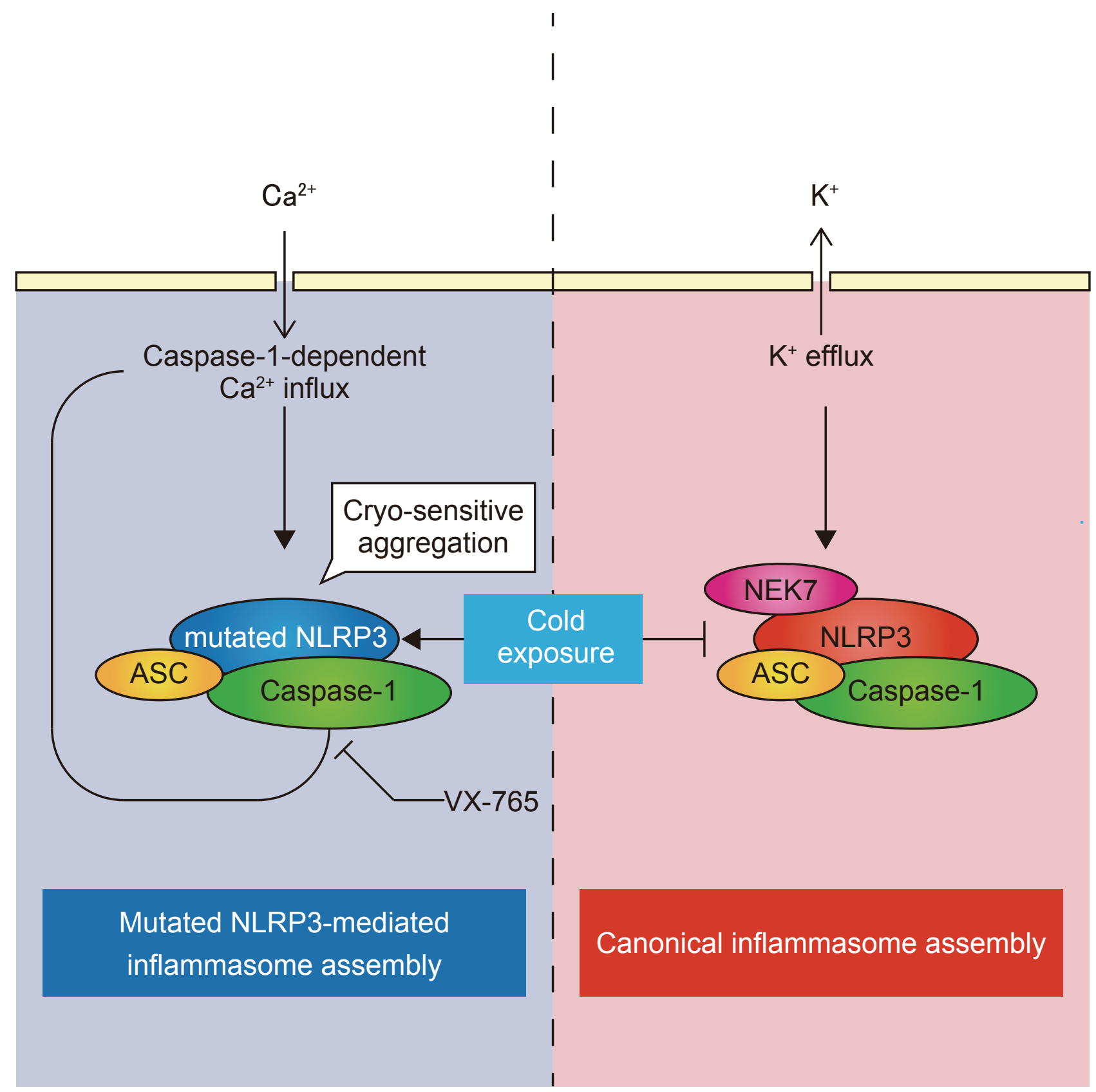

Figure 7. Model of CAPS-associated NLRP3 mutants-mediated inflammasome assembly.

The mutated NLRP3 forms cryo-sensitive aggregates which trigger inflammasome assembly. The mutated NLRP3-mediated inflammasome assembly is sensitive to $\mathrm{Ca}^{2+}$ whereas canonical NLRP3 inflammasome assembly is dependent on $\mathrm{K}^{+}$efflux. The inhibition of caspase- 1 prevents the mutated NLRP3-mediated $\mathrm{Ca}^{2+}$ influx and inflammasome assembly. 
The formation of cryo-sensitive aggregates by CAPS-associated NLRP3 mutants is a significant finding of this study. Oligomerization or polymerization is a common feature of domains contained in inflammasome components. Both CARD in ASC and caspase-1 and PYD in ASC and NLRP3 form filamentous assemblies (Masumoto et al., 1999; Lu et al., 2014; Karasawa et al., 2015; Stutz et al., 2017). In addition, full-length ASC, which has both PYD and CARD, forms a large aggregate called speck. Therefore, aggregation of CAPS-associated NLRP3 mutants seems to be mediated by their PYD-PYD interaction. However, the mechanisms by which CAPS-associated NLRP3 mutants, which typically occur in other domains including NACHT domain and LRR, promote aggregation and affect their cryosensitivity have remained unclear. According to the structural analysis, an unstructured domain is present between PYD and NACHT. Although the structure of NLRP3 without PYD has recently been determined by cryo-electron microscopy, the structure of full-length NLRP3 and the effect of CAPS-associated mutation on it is unclear (Sharif et al., 2019). This information would be useful for clarifying how CAPS-associated NLRP3 mutants form aggregates.

With regard to cryo-sensitivity, recent studies have suggested that the formation of aggregates and LLPS is modulated by conditions including temperature and $\mathrm{pH}$ (Alberti et al., 2019; Riback et al., 2020). These factors shift the threshold of aggregation and LLPS under a constant protein concentration. In the present study, the frequency of foci formation by mutated NLRP3 was weakly associated with its expression levels. Furthermore, increased expression of mutated NLRP3 dose-dependently promoted inflammasome assembly. The temperature and its expression levels seem to be an essential determinant of the aggregation of mutated NLRP3.

Increasing evidence suggests that $\mathrm{K}^{+}$efflux is a main upstream event of NLRP3 inflammasome activation (Munoz-Planillo et al., 2013; He et al., 2016a). Although the precise mechanism underlying $\mathrm{K}^{+}$efflux-mediated NLRP3 inflammasome assembly is still unclear, NEK7 has been shown to interact with NLRP3 directly and promote inflammasome assembly as a downstream of $\mathrm{K}^{+}$efflux (He et al., 2016b). Unexpectedly, we demonstrated that inflammasome activation induced by NLRP3-L353P is not prevented by supplementation with extracellular $\mathrm{K}^{+}$or a deficiency of NEK7, indicating that $\mathrm{K}^{+}$efflux is dispensable for inflammasome activation induced by FCAS-associated NLRP3 mutant. Instead, our data 
clearly showed that both NLRP3 aggregation and inflammasome assembly induced by NLRP3L353P are dependent on the presence of $\mathrm{Ca}^{2+}$. Several studies indicate that $\mathrm{Ca}^{2+}$ is another upstream signal of NLRP3 inflammasome activation (Lee et al., 2012; Murakami et al., 2012; Rossol et al., 2012; Horng, 2014). Further studies are necessary to elucidate whether the previously identified mechanism of $\mathrm{Ca}^{2+}$-mediated WT NLRP3 inflammasome activation shares the mechanism with inflammasome activation induced by CAPS-associated NLRP3 mutants. However, the $\mathrm{Ca}^{2+}$-sensitive NLRP3 aggregation appear to be distinct from canonical inflammasome assembly because the stimulation with nigericin failed to form NLRP3 aggregates.

Of note, we showed that the elevation of intracellular $\mathrm{Ca}^{2+}$ induced by NLRP3L353P was dependent on caspase-1 activity. Recent studies have suggested that gasdermin pore formation induced by caspase activation regulates the influx of $\mathrm{Ca}^{2+}$ (de Vasconcelos et al., 2019). Broz and his colleagues have suggested that the $\mathrm{Ca}^{2+}$ influx induced by GSDMD pore formation initiates membrane repair by ESCRT complex, which negatively regulates pyroptosis (Rühl et al., 2018). Thus, the elevation of intracellular $\mathrm{Ca}^{2+}$ by GSDMD pore seems to regulate various cellular functions. In the present study, pharmacological caspase-1 inhibition prevents the elevation of intracellular $\mathrm{Ca}^{2+}$ and ASC oligomerization and speck formation. Therefore, we consider that CAPS-associated NLRP3 mutant forms cryo-sensitive inflammasome assemblies, which trigger caspase-1-mediated feed-forward loop of $\mathrm{Ca}^{2+}$ influx, leading to incremental inflammasome assembly. These findings also suggest that caspase-1 inhibition could be a potential target of inflammasome assembly induced by CAPS-associated NLRP3 mutants.

In the present study, we investigated the mechanisms of cryo-sensitive inflammasome assembly in CAPS-associated NLRP3 mutants. However, this study has a few limitations. First, to analyze the function of mutated NLRP3, we used mutated NLRP3 expressing under an inducible promoter or in ASC KO cells because the expression of mutated NLRP3 induces pyroptotic cell death. To clarify the dynamics of endogenously expressed NLRP3, a study using a knock-in model would be required. Second, the aggregation of NLRP3 was analyzed by 
fusion protein with mNeonGreen. A biochemical analysis of aggregation using mutated NLRP3 without any tags or fluorescent proteins is also required in the future.

In conclusion, we found that CAPS-associated NLRP3 mutants form cryo-sensitive aggregates, which can function as the scaffold for NLRP3 inflammasome activation. The aggregation of mutated NLRP3 is not dependent on $\mathrm{K}^{+}$efflux but rather is regulated by intracellular $\mathrm{Ca}^{2+}$ levels. We expect that our findings would be valuable for the development of novel therapies for CAPS.

\section{Author Contributions}

Conceptualization, T.Ka., and M.T.; Methodology, E.A., T.Ka., and S.W.; Validation, T.Ko. ,Y.M., and N.Y; Investigation, T.Ka., E.A., S.W., T.Ko., and C.B.; Resources, E.A., T.Ka; Writing- Original Draft, T.Ka.; Writing- Review \& Editing, T.Ka., M.T.; Visualization, T.Ka.; Supervision, T.Ko., T.M., and M.T.; Project Administration, T.Ka., and M.T.; Funding Acquisition, T.Ka. and M.T.

\section{Acknowledgments}

This study was supported by the Japan Society for the Promotion of Science (JSPS) through the Grants-in-Aid for Scientific Research (C), (18K08112, M.T.; 18K08485, T.Kar.), Grantsin-Aid for Scientific Research on Innovative Areas (Thermal Biology) (16H01395. M.T.), the Agency for Medical Research and Development-Core Research for Evolutional Science and Technology (AMED-CREST) (M.T.), and the Ministry of Education, Culture, Sports, Science and Technology (MEXT)-supported program for Private University Research Branding Project (M.T.). We are grateful to Dr. Kunitoshi Uchida and Dr. Jun Fujita for their valuable suggestions. We thank Naoko Sugaya, Masako Sakurai, and Rumiko Ochiai for their technical assistance. 


\section{METHODS}

KEY RESOURCES TABLE

\begin{tabular}{|c|c|c|}
\hline REAGENT or RESOURCE & SOURCE & IDENTIFIER \\
\hline \multicolumn{3}{|l|}{ Antibodies } \\
\hline Mouse monoclonal anti-NLRP3 & Adipogen & AG-20B-0014 \\
\hline Rabbit polyclonal anti-ASC & Adipogen & AG-25B-0006 \\
\hline Rabbit polyclonal anti-IL-1 $\beta$ & Santa Cruz & sc-7884 \\
\hline Mouse monoclonal anti- $\beta$-actin & Sigma-Aldrich & A5441 \\
\hline \multicolumn{3}{|c|}{ Chemicals, peptides, and recombinant proteins } \\
\hline MCC950 & AdipoGen & $\begin{array}{l}\text { AG-CR1- } \\
\text { 3615-M005 }\end{array}$ \\
\hline DRAQ5 & Biolegend & 424101 \\
\hline Probenecid & Cayman & 14981 \\
\hline DAPI & DOJINDO & D523 \\
\hline Fura-2/AM & DOJINDO & F015 \\
\hline Hoechst33342 & DOJINDO & $\mathrm{H} 342$ \\
\hline PEI MAX & Polyscience & $24765-1$ \\
\hline VX765 & Selleck & S2228 \\
\hline Pluronic F127 & Sigma-Aldrich & P2443 \\
\hline Puromycin & Sigma-Aldrich & P8833 \\
\hline Fluo-8 & Santa Cruz & Sc-362562 \\
\hline Bis(sulfosuccinimidyl)suberate & Thermo Fisher Scientific & 21580 \\
\hline SYTOX Deep Red & Thermo Fisher Scientific & S11380 \\
\hline Doxycycline Hydrochloride n-Hydrate & Wako & 049-31121 \\
\hline Phorbol 12-Myristate 13-Acetate & Wako & $162-23591$ \\
\hline \multicolumn{3}{|l|}{ Critical commercial assays } \\
\hline Lentiviral qPCR Titration Kit & $\begin{array}{l}\text { Applied Biological } \\
\text { Materials }\end{array}$ & \#LV900 \\
\hline Human IL-1 beta/IL-1F2 DuoSet ELISA & R \& D Systems & DY201 \\
\hline Super Script VILO cDNA Synthesis kit & Thermo Fisher Scientific & \\
\hline \multicolumn{3}{|l|}{ Deposited data } \\
\hline \multicolumn{3}{|l|}{ N.A. } \\
\hline Experimental models: Cell lines & & \\
\hline
\end{tabular}




\begin{tabular}{|c|c|c|}
\hline LentiX293T & Takara Bio & Z2180N \\
\hline Hela & ATCC & CCL-2 \\
\hline EF1-NLRP3-WT-mNeonGreen-HeLa & This manuscript & N/A \\
\hline EF1-NLRP3-L353P-mNeonGreen-HeLa & This manuscript & N/A \\
\hline EF1-NLRP3-D303N-mNeonGreen-HeLa & This manuscript & $\mathrm{N} / \mathrm{A}$ \\
\hline EF1-ASC-GFP-HeLa & This manuscript & $\mathrm{N} / \mathrm{A}$ \\
\hline THP-1 & ATCC & TIB-202 \\
\hline ASC KO THP-1 & Aizawa et al., 2020 & N/A \\
\hline EF1-NLRP3-WT-mNeonGreen/ASC KO THP-1 & This manuscript & N/A \\
\hline EF1-NLRP3-L353P-mNeonGreen/ASC KO THP-1 & This manuscript & N/A \\
\hline EF1-NLRP3-D303N-mNeonGreen/ASC KO THP-1 & This manuscript & N/A \\
\hline TRE-NLRP3-WT-THP-1 & This manuscript & N/A \\
\hline TRE-NLRP3-L353P-THP-1 & This manuscript & $\mathrm{N} / \mathrm{A}$ \\
\hline TRE-NLRP3-L353P/NEK7 KO THP-1 & This manuscript & $\mathrm{N} / \mathrm{A}$ \\
\hline TRE-NLRP3-D303N-THP-1 & Aizawa et al., 2020 & $\mathrm{~N} / \mathrm{A}$ \\
\hline EF1-ASC-GFP/TRE-NLRP3-L353P-THP-1 & This manuscript & $\mathrm{N} / \mathrm{A}$ \\
\hline EF1-ASC-BFP/TRE-NLRP3-L353P-THP-1 & This manuscript & $\mathrm{N} / \mathrm{A}$ \\
\hline EF1-ASC-BFP/TRE-NLRP3-WT-mNeonGreen-THP-1 & This manuscript & N/A \\
\hline $\begin{array}{l}\text { EF1-ASC-BFP/TRE-NLRP3-L353P-mNeonGreen- } \\
\text { THP-1 }\end{array}$ & This manuscript & N/A \\
\hline \multicolumn{3}{|l|}{ Oligonucleotides } \\
\hline $\begin{array}{lccc}\text { sgRNA } & \text { sequence } & \text { for } & \text { GFP- } \\
\text { GAGCTGGACGGCGACGTAAA } & & \end{array}$ & Aizawa et al., 2020 & $\mathrm{~N} / \mathrm{A}$ \\
\hline $\begin{array}{lccc}\text { sgRNA } & \text { sequence } & \text { for } & \text { ASC- } \\
\text { TCTTGAGCTCCTCGGCGGTC } & & \end{array}$ & Aizawa et al., 2020 & $\mathrm{~N} / \mathrm{A}$ \\
\hline $\begin{array}{lcll}\text { sgRNA sequence } & \text { for } & \text { NEK7\#1- } \\
\text { ATTACAGAAGGCCTTACGAC } & & \end{array}$ & This manuscript & $\mathrm{N} / \mathrm{A}$ \\
\hline $\begin{array}{lcll}\text { sgRNA } & \text { sequence } & \text { for } & \text { NEK7\#2- } \\
\text { ATAGCCCATATCCGGTCGTA } & & \end{array}$ & This manuscript & N/A \\
\hline \multicolumn{3}{|l|}{ Recombinant DNA } \\
\hline CSCAMCS & RIKEN BRC & RDB05963 \\
\hline CSEF1-NLRP3-WT-mNeonGreen & This manuscript & N/A \\
\hline CSEF1-NLRP3-L353P-mNeonGreen & This manuscript & $\mathrm{N} / \mathrm{A}$ \\
\hline CSEF1-NLRP3-D303N-mNeonGreen & This manuscript & $\mathrm{N} / \mathrm{A}$ \\
\hline
\end{tabular}




\begin{tabular}{|l|l|l|}
\hline CSEF1-ASC-GFP & This manuscript & N/A \\
\hline CSEF1-ASC-BFP & This manuscript & N/A \\
\hline CSIV-TRE-RfA-CMV-KT & RIKEN BRC & RDB12876 \\
\hline CSIV-TRE-NLRP3-WT-CMV-KT & This manuscript & N/A \\
\hline CSIV-TRE-NLRP3-L353P-CMV-KT & This manuscript & N/A \\
\hline CSIV-TRE-NLRP3-D303N-CMV-KT & Aizawa et al., 2020 & N/A \\
\hline CSIV-TRE-NLRP3-WT-mNeonGreen-CMV-KT & This manuscript & N/A \\
\hline CSIV-TRE-NLRP3-L353P-mNeonGreen -CMV-KT & This manuscript & N/A \\
\hline LentiCRISPRv2 & Addgene & \#52961 \\
\hline LentiCRISPRv2 sgGFP & Aizawa et al., 2020 & N/A \\
\hline LentiCRISPRv2 sgASC & Aizawa et al., 2020 & N/A \\
\hline LentiCRISPRv2 sgNEK7 & This manuscript & N/A \\
\hline Software and algorithms & & RRID: \\
\hline GraphPad Prism 6 & Graph Pad Software & RRID:SCR_0 \\
\hline ImageJ/FIJI (2.1.0/1.53C) & & 02798 \\
\hline IUpred2A & Schindelin et al., 2012 & RRID:SCR_0 \\
\hline R version 4.0.2 & Részáros et al., 2018 & RRID:SCR_0 \\
\hline & & 14632 \\
\hline
\end{tabular}

\section{$\underline{\text { Plasmids }}$}

Polymerase chain reaction (PCR)-generated cDNAs encoding human NLRP3 were subcloned into pENTR4 vector. The mutated NLRP3-D303N and NLRP3-L353P were generated using the PrimeSTAR Mutagenesis Basal kit (Takara Bio, Shiga, Japan) (Aizawa et al., 2020). The primers for introducing mutations were as follows: D303N (forward, 5'GGCTTCAATGAGCTGCAAGGTGCCTTTGACGAG-3'; reverse, 
KT (kindly provided by Dr. H. Miyoshi, RDB12876, RIKEN BRC, Tsukuba, Japan) with LR clonase (Thermo Fisher Scientific). To develop NLRP3-mNeonGreen or ASC-BFP-expressing lentiviral vector, PCR-generated NLRP3-WT, NLRP3-L353P, NLRP3-D303N, ASC, mNeonGreen, moxBFP (a gift from Erik Snapp; Addgene plasmid \#68064) were Gibson subcloned into CS-EF-1 (derived from CS-CA-MCS; RIKEN BRC). The sgRNA targeting NEK7 was designed with CRISPR direct (http://crispr.dbcls.jp) and subcloned into LentiCRISPRv2, which was a gift from Feng Zhang (Addgene plasmid \#52961; http://n2t.net/addgene: 52961; RRID: Addgene_52961).

\section{Cell culture}

HeLa cells were cultured in Dulbecco's modified Eagle's medium (DMEM, Wako, Osaka, Japan) supplemented with 10\% fetal calf serum (FCS) and antibiotics. THP-1 cells were cultured in RPMI640 (Sigma, St Louis, MO, USA) supplemented with 10\% fetal calf serum (FCS) and antibiotics. THP-1 macrophages were differentiated with $200 \mathrm{nM}$ phorbol-12myristate-13-acetate (PMA) for $24 \mathrm{~h}$. LentiX293T cells were obtained from TAKARA (Takara Bio, Shiga, Japan) and cultured in DMEM supplemented with 10\% FCS, $1 \mathrm{mM}$ sodium pyruvate, and antibiotics. Unless otherwise indicated, cells were cultured at $37^{\circ} \mathrm{C}$ in $5 \% \mathrm{CO}_{2}$.

\section{Lentiviral preparation}

LentiX293T cells were co-transfected with self-inactivating vectors, $\mathrm{pLP} 1, \mathrm{pLP} 2$, and pVSVG using PEI MAX (Polysciences, Warrington, PA, USA) to prepare the lentiviral vectors. Culture media containing the lentiviral vectors were collected 3 days after transfection. The collected media were filtered with a $0.45-\mu \mathrm{m}$ filter and ultracentrifuged at $21,000 \mathrm{rpm}$ using a Type 45 Ti rotor (Beckman Coulter, Brea, CA, USA), and the pellets were resuspended in phosphate-buffered saline (PBS) containing 5\% FCS. The lentivirus titer was measured using a Lentivirus qPCR Titer kit (Applied Biological Materials, Richmond, BC, Canada). For lentiviral transduction, the cells were incubated with purified lentiviral vectors in the presence of $8 \mu \mathrm{g} / \mathrm{mL}$ polybrene (Sigma). The details of the developed cells are described in the key resource table. 


\section{Treatment of reagents and cold exposure}

The transduced THP-1 cells were differentiated with $200 \mathrm{nM}$ PMA for $24 \mathrm{~h}$ and treated with DOX (Wako) or nigericin (InvivoGen) at the indicated concentrations. Next, cells were cultured at $37^{\circ} \mathrm{C}$ or $32^{\circ} \mathrm{C}$. Cells were then pretreated with inhibitors including CA- 074 (Wako), MCC950 (Adipogen, San Diego, CA), VX-765 (Selleck), and Z-VAD-FMK (MBL) for $30 \mathrm{~min}$ prior to cold exposure.

\section{Confocal microscopy}

For imaging of fixed cells, the transduced cells were seeded on an 8 -well chamber slide (Matsunami Glass Ind., Ltd., Osaka, Japan), and then fixed with neutral buffered formalin or $1 \%$ paraformaldehyde and stained with $1 \mu \mathrm{g} / \mathrm{mL}$ 4',6-diamidino-2-phenylindole, dihydrochloride (DAPI; Dojindo). For live-cell imaging, cells were seeded at $1 \times 10^{5}$ cells/well on 8-well cover glass chambers (IWAKI, Shizuoka, Japan) and labeled with Hoechst33342 for 20 min before treatment. The images were captured using confocal microscopy (FLUOVIEW FV10i; Olympus, Tokyo, Japan).

\section{$\underline{\text { High content analysis }}$}

The transduced HeLa cells or THP-1 cells were seeded on 96-well plates and treated with the indicated stimuli. For analysis of fixed cells, nuclei were stained with DAPI after fixation by $1 \%$ paraformaldehyde. For live-cell imaging, cells were stained with DRAQ5 (Biolegend, San Diego, CA) and analyzed by an Operetta CLS high-content analysis system (PerkinElmer, Waltham, MA).

\section{FRAP analysis}

The transduced HeLa cells were seeded on 8-well cover glass chambers (IWAKI), cultured at $32^{\circ} \mathrm{C}$ for $24 \mathrm{~h}$, and analyzed by FV1000 confocal microscopy (Olympus) at $32^{\circ} \mathrm{C}$. Images were captured using an UPLA SAPO 60XO objective. The GFP and mNeonGreen signals were captured using a line sequential scan setting with excitation laser lines at $488 \mathrm{~nm}$. 
For FRAP analysis, a $1 \mathrm{sec}$ pulse of the $488 \mathrm{~nm}$ laser line at $5 \%$ power was used to bleach the NLRP3-mNeonGreen foci. A $5 \mathrm{sec}$ pulse of 488 laser line at 30\% power was used to bleach the ASC-GFP specks. The changing of fluorescence was monitored by imaging every $0.2 \mathrm{msec}$.

\section{$\underline{I L-1 \beta \text { secretion assay }}$}

Cells were seeded into 96 -well plates at $5 \times 10^{4}$ cells/well. After the indicated treatments, culture supernatants were collected and the IL-1 $\beta$ levels were measured by enzymelinked immunosorbent assay (ELISA) using a commercial kit (R\&D Systems, Minneapolis, MN, USA). The supernatants were precipitated with ice-cold acetone and resolved in $1 \times$ Laemmli buffer for Western blot analysis.

\section{Western blot analysis}

Samples were separated by sodium dodecyl sulfate-polyacrylamide electrophoresis (SDS-PAGE) and transferred to PVDF membranes. After blocking with Blocking One (Nacalai Tesque, Kyoto, Japan) for $30 \mathrm{~min}$, the membranes were incubated overnight at $4^{\circ} \mathrm{C}$ with the following primary antibodies (Abs): anti-ASC (AL-177; Adipogen), anti- $\beta$ actin (clone AC-15; Sigma), anti-Caspase-1 (3866; Cell Signaling Technology), anti-IL-1 $\beta$ (H153; Santa Cruz Biotechnology), and anti-NLRP3 (clone Cryo-2; Adipogen). As secondary Abs, HRP-goat antimouse Superclonal IgG (Thermo Fisher Scientific) or HRP-goat anti-rabbit IgG (Cell Signaling Technology) was incubated with membrane for $1 \mathrm{~h}$. After being washed with TBS-Tween, immunoreactive bands were visualized using Western BLoT Quant HRP Substrate (Takara Bio) or Western BLoT Ultra Sensitive HRP Substrate (Takara Bio).

\section{$\underline{\text { ASC-oligomerization assay }}$}

Cells were lysed in $0.5 \%$ Triton X-100 buffer (20 mM Tris $\mathrm{HCl}, 10 \mathrm{mM} \mathrm{KCl}, 1.5$ $\mathrm{mM} \mathrm{MgCl} 2,1 \mathrm{mM}$ EDTA, $1 \mathrm{mM}$ EGTA, $320 \mathrm{mM}$ sucrose, and 0.5\% Triton X-100) for $20 \mathrm{~min}$. Lysates were then centrifuged at $5000 \mathrm{xg}$ for $10 \mathrm{~min}$. The insoluble pellets were reacted with 2 $\mathrm{mM}$ bis(sulfosuccinimidyl)suberate (BS3) (Thermo Fisher Scientific) for 30 min and the reactions were terminated by an excess amount of glycine. 


\section{Reverse transcription and real-time PCR}

Total RNA was prepared using ISOGEN (Nippon Gene Co., Tokyo, Japan) according to the manufacturer's instructions. Total RNA was reverse-transcribed using a SuperScript VILO cDNA Synthesis kit (Life Technologies). Real-time PCR was performed using SYBR Premix Ex Taq II (Takara Bio). The primers used in the assay were as follows: NEK7 (forward, 5'-GCCTTACGACCGGATATGGG-3'; reverse， 5'-CACTAAATTGTCCGCGACCAA-3'), and ACTB (forward, 5'- GGCACTCTTCCAGCCTTCCTTC-3'; reverse, 5'GCGGATGTCCACGTCACACTTCA-3').

\section{$\underline{C a^{2+} \text {-imaging using Fluo-8 }}$}

Cells were seeded at $1 \times 10^{5}$ cells/well on an 8 -well cover glass chamber (IWAKI). Fluo-8 (Santa Cruz Biotechnology) was loaded at $4 \mu \mathrm{M}$ for $60 \mathrm{~min}$ in the presence of $0.04 \%$ Pluronic F127 (Sigma)and $1.25 \mathrm{mM}$ probenecid (Cayman). After removal of the loading medium, cells were treated with DOX in the presence of $1.25 \mathrm{mM}$ probenecid. Z-stack timelapse images at $37^{\circ} \mathrm{C}$ were captured using confocal microscopy (FLUOVIEW FV10). To normalize the cell number, nuclei were labeled with Hoechst $33342(1 \mu \mathrm{g} / \mathrm{mL})$ or DRAQ5. For detection of dying cells, images were captured in the presence of 100 nM SYTOX Deep Red.

\section{Fura2 Assay}

Cells were seeded at $5 \times 10^{4}$ cells/well into 96 well plates, and loaded with $3 \mu \mathrm{M}$ fura 2-AM (Dojindo, Kumamoto, Japan) for $30 \mathrm{~min}$. After cells were treated with the indicated reagents, fluorescence intensity (Excitation:340 or 380, Emission:510 nm) was measured by using a multimode microplate reader (Spark; TECAN, Switzerland) at $37^{\circ} \mathrm{C}$ or $32^{\circ} \mathrm{C}$.

\section{$\underline{\text { Statistical analysis }}$}

Data are expressed as mean \pm standard deviation (SD). Differences between two groups were determined by Student's t-test. Differences between multiple group means were determined by two-way analysis of variance (ANOVA) combined with the Tukey's post hoc 
test. Differences between multiple groups with repeated measurements were evaluated by repeated one-way ANOVA or repeated two-way ANOVA combined with the post hoc test. Analyses were performed using GraphPad Prism 6 software (Graph Pad Software, La Jolla, CA, USA) or R version 4.0.2 (https://www.r-project.org). A p-value of $<0.05$ was considered statistically significant. Biological replicates indicate replicates of the same experiment conducted upon separately seeded culture on separate days. The number of biological replicates is described in the figure legend. For plate reader-based assay, $\mathrm{n}$ represents replicates that were acquired from different cells. In live-cell imaging assay, $\mathrm{n}$ represents replicates that were acquired from each cell through multiple set of experiments.

\section{Reference}

Aizawa, E., Karasawa, T., Watanabe, S., Komada, T., Kimura, H., Kamata, R., Ito, H., Hishida, E., Yamada, N., Kasahara, T., et al. 2020. GSDME-Dependent Incomplete Pyroptosis Permits Selective IL-1 $\alpha$ Release under Caspase-1 Inhibition. iScience 23, 101070. doi: 10.1016/j.isci.2020.101070

Alberti, S., Gladfelter, A., and Mittag, T. 2019. Considerations and Challenges in Studying Liquid-Liquid Phase Separation and Biomolecular Condensates. Cell 176, 419-434. doi: 10.1016/j.cell.2018.12.035

Broz, P., Pelegrín, P., and Shao, F. 2020. The gasdermins, a protein family executing cell death and inflammation. Nat Rev Immunol 20, 143-157. doi: 10.1038/s41577-019-0228-2

Brydges, S.D., Broderick, L., McGeough, M.D., Pena, C.A., Mueller, J.L., and Hoffman, H.M. 2013. Divergence of IL-1, IL-18, and cell death in NLRP3 inflammasomopathies. J Clin Invest 123, 4695-4705. doi: 10.1172/jci71543

Brydges, S.D., Mueller, J.L., McGeough, M.D., Pena, C.A., Misaghi, A., Gandhi, C., Putnam, C.D., Boyle, D.L., Firestein, G.S., Horner, A.A., et al. 2009. Inflammasome-mediated disease animal models reveal roles for innate but not adaptive immunity. Immunity 30, 875-887. doi: 10.1016/j.immuni.2009.05.005

Coll, R.C., Robertson, A.A., Chae, J.J., Higgins, S.C., Munoz-Planillo, R., Inserra, M.C., Vetter, I., Dungan, L.S., Monks, B.G., Stutz, A., et al. 2015. A small-molecule inhibitor of the NLRP3 
inflammasome for the treatment of inflammatory diseases. Nat Med 21, 248-255. doi: $10.1038 / \mathrm{nm} .3806$.

Cordero, M.D., Alcocer-Gómez, E., and Ryffel, B. 2018. Gain of function mutation and inflammasome driven diseases in human and mouse models. J Autoimmun 91, 13-22. doi: 10.1016/j.jaut.2018.03.002

de Vasconcelos, N.M., Van Opdenbosch, N., Van Gorp, H., Parthoens, E., and Lamkanfi, M. 2019. Single-cell analysis of pyroptosis dynamics reveals conserved GSDMD-mediated subcellular events that precede plasma membrane rupture. Cell Death Differ 26, 146-161. doi: $10.1038 / \mathrm{s} 41418-018-0106-7$

Duewell, P., Kono, H., Rayner, K.J., Sirois, C.M., Vladimer, G., Bauernfeind, F.G., Abela, G.S., Franchi, L., Nunez, G., Schnurr, M., et al. 2010. NLRP3 inflammasomes are required for atherogenesis and activated by cholesterol crystals. Nature 464, 1357-1361. doi: 10.1038 /nature08938

Feldmann, J., Prieur, A.M., Quartier, P., Berquin, P., Certain, S., Cortis, E., Teillac-Hamel, D., Fischer, A., and de Saint Basile, G. (2002). Chronic infantile neurological cutaneous and articular syndrome is caused by mutations in CIAS1, a gene highly expressed in polymorphonuclear cells and chondrocytes. Am J Hum Genet 71, 198-203. doi: $10.1086 / 341357$

He, Y., Hara, H., and Núñez, G. 2016a. Mechanism and Regulation of NLRP3 Inflammasome Activation. Trends in biochemical sciences 41, 1012-1021. doi: 10.1016/j.tibs.2016.09.002 He, Y., Zeng, M.Y., Yang, D., Motro, B., and Núñez, G. 2016b. NEK7 is an essential mediator of NLRP3 activation downstream of potassium efflux. Nature 530, 354-357. doi: 10.1038/nature16959

Horng, T. 2014. Calcium signaling and mitochondrial destabilization in the triggering of the NLRP3 inflammasome. Trends Immunol 35, 253-261. doi: 10.1016/j.it.2014.02.007

Karasawa, T., Kawashima, A., Usui, F., Kimura, H., Shirasuna, K., Inoue, Y., Komada, T., Kobayashi, M., Mizushina, Y., Sagara, J., et al. 2015. Oligomerized CARD16 promotes caspase-1 assembly and IL-1 $\beta$ processing. FEBS open bio 5, 348-356. doi: 10.1016/j.fob.2015.04.011 
Karasawa, T., and Takahashi, M. 2017. Role of NLRP3 Inflammasomes in Atherosclerosis. J Atheroscler Thromb 24, 443-451. doi: 10.5551/jat.RV17001

Komada, T., Usui, F., Kawashima, A., Kimura, H., Karasawa, T., Inoue, Y., Kobayashi, M., Mizushina, Y., Kasahara, T., Taniguchi, S., et al. 2015. Role of NLRP3 Inflammasomes for Rhabdomyolysis-induced Acute Kidney Injury. Sci Rep 5, 10901. doi: 10.1038/srep10901 Komada, T., Usui, F., Shirasuna, K., Kawashima, A., Kimura, H., Karasawa, T., Nishimura, S., Sagara, J., Noda, T., Taniguchi, S., et al. 2014. ASC in Renal Collecting Duct Epithelial Cells Contributes to Inflammation and Injury after Unilateral Ureteral Obstruction. Am J Pathol 184, 1287-1298. doi: 10.1016/j.ajpath.2014.01.014

Kuemmerle-Deschner, J.B. 2015. CAPS--pathogenesis, presentation and treatment of an autoinflammatory disease. Semin Immunopathol 37, 377-385. doi: 10.1007/s00281-015-04917

Kuemmerle-Deschner, J.B., Ozen, S., Tyrrell, P.N., Kone-Paut, I., Goldbach-Mansky, R., Lachmann, H., Blank, N., Hoffman, H.M., Weissbarth-Riedel, E., Hugle, B., et al. 2017. Diagnostic criteria for cryopyrin-associated periodic syndrome (CAPS). Ann Rheum Dis 76, 942-947. doi: 10.1136/annrheumdis-2016-209686

Lee, G.S., Subramanian, N., Kim, A.I., Aksentijevich, I., Goldbach-Mansky, R., Sacks, D.B., Germain, R.N., Kastner, D.L., and Chae, J.J. 2012. The calcium-sensing receptor regulates the NLRP3 inflammasome through $\mathrm{Ca} 2+$ and cAMP. Nature 492, 123-127. doi: $10.1038 /$ nature11588

Liu, X., Zhang, Z., Ruan, J., Pan, Y., Magupalli, V.G., Wu, H., and Lieberman, J. 2016. Inflammasome-activated gasdermin D causes pyroptosis by forming membrane pores. Nature 535, 153-158. doi: 10.1038/nature18629

Lu, A., Magupalli, V.G., Ruan, J., Yin, Q., Atianand, M.K., Vos, M.R., Schroder, G.F., Fitzgerald, K.A., Wu, H., and Egelman, E.H. 2014. Unified Polymerization Mechanism for the Assembly of ASC-Dependent Inflammasomes. Cell 156, 1193-1206. doi: 10.1016/j.cell.2014.02.008

Martinon, F., Petrilli, V., Mayor, A., Tardivel, A., and Tschopp, J. 2006. Gout-associated uric acid crystals activate the NALP3 inflammasome. Nature 440, 237-241. doi: 


\section{$10.1038 /$ nature 04516}

Masumoto, J., Taniguchi, S., Ayukawa, K., Sarvotham, H., Kishino, T., Niikawa, N., Hidaka, E., Katsuyama, T., Higuchi, T., and Sagara, J. 1999. ASC, a novel 22-kDa protein, aggregates during apoptosis of human promyelocytic leukemia HL-60 cells. J Biol Chem 274, 3383533838. doi: 10.1074/jbc.274.48.33835.

Munoz-Planillo, R., Kuffa, P., Martinez-Colon, G., Smith, B.L., Rajendiran, T.M., and Nunez, G. 2013. $\mathrm{K}(+)$ efflux is the common trigger of NLRP3 inflammasome activation by bacterial toxins and particulate matter. Immunity $38,1142-1153$. doi: 10.1016/j.immuni.2013.05.016

Murakami, T., Ockinger, J., Yu, J., Byles, V., McColl, A., Hofer, A.M., and Horng, T. 2012. Critical role for calcium mobilization in activation of the NLRP3 inflammasome. Proc Natl Acad Sci USA 109, 11282-11287. doi: 10.1073/pnas.1117765109

Riback, J.A., Zhu, L., Ferrolino, M.C., Tolbert, M., Mitrea, D.M., Sanders, D.W., Wei, M.T., Kriwacki, R.W., and Brangwynne, C.P. 2020. Composition-dependent thermodynamics of intracellular phase separation. Nature 581, 209-214. doi: 10.1038/s41586-020-2256-2

Rosengren, S., Mueller, J.L., Anderson, J.P., Niehaus, B.L., Misaghi, A., Anderson, S., Boyle, D.L., and Hoffman, H.M. 2007. Monocytes from familial cold autoinflammatory syndrome patients are activated by mild hypothermia. J Allergy Clin Immunol 119, 991-996. doi: 10.1016/j.jaci.2006.12.649

Rossol, M., Pierer, M., Raulien, N., Quandt, D., Meusch, U., Rothe, K., Schubert, K., Schöneberg, T., Schaefer, M., Krügel, U., et al. 2012. Extracellular Ca2+ is a danger signal activating the NLRP3 inflammasome through G protein-coupled calcium sensing receptors. Nat Commun 3, 1329. doi: 10.1038/ncomms2339

Rühl, S., Shkarina, K., Demarco, B., Heilig, R., Santos, J.C., and Broz, P. 2018. ESCRTdependent membrane repair negatively regulates pyroptosis downstream of GSDMD activation. Science 362, 956-960. doi: 10.1126/science.aar7607

Schroder, K., and Tschopp, J. 2010. The inflammasomes. Cell 140, 821-832. doi:10.1016/j.cell.2010.01.040

Sharif, H., Wang, L., Wang, W.L., Magupalli, V.G., Andreeva, L., Qiao, Q., Hauenstein, A.V., Wu, Z., Núñez, G., Mao, Y., et al. 2019. Structural mechanism for NEK7-licensed activation of 
bioRxiv preprint doi: https://doi.org/10.1101/2021.10.05.463273; this version posted October 29,2021 . The copyright holder for this preprint (which was not certified by peer review) is the author/funder, who has granted bioRxiv a license to display the preprint in perpetuity. It is made available under aCC-BY-NC-ND 4.0 International license.

NLRP3 inflammasome. Nature 570, 338-343. doi: 10.1038/s41586-019-1295-z

Stutz, A., Kolbe, C.C., Stahl, R., Horvath, G.L., Franklin, B.S., van Ray, O., Brinkschulte, R., Geyer, M., Meissner, F., and Latz, E. 2017. NLRP3 inflammasome assembly is regulated by phosphorylation of the pyrin domain. J Exp Med 214, 1725-1736. doi: 10.1084/jem.20160933 Usui, F., Shirasuna, K., Kimura, H., Tatsumi, K., Kawashima, A., Karasawa, T., Hida, S., Sagara, J., Taniguchi, S., and Takahashi, M. 2012. Critical role of caspase-1 in vascular inflammation and development of atherosclerosis in Western diet-fed apolipoprotein E-deficient mice. Biochem Biophys Res Commun 425, 162-168. doi: 10.1016/j.bbrc.2012.07.058

Usui, F., Shirasuna, K., Kimura, H., Tatsumi, K., Kawashima, A., Karasawa, T., Yoshimura, K., Aoki, H., Tsutsui, H., Noda, T., et al. 2015. Inflammasome activation by mitochondrial oxidative stress in macrophages leads to the development of angiotensin II-induced aortic aneurysm. Arterioscler Thromb Vasc Biol 35, 127-136. doi: 10.1161/ATVBAHA.114.303763 